\title{
Coincidence Detection within the Excitable Rat Olfactory Bulb Granule Cell Spines
}

\author{
(1)S. Sara Aghvami, ${ }^{1,2}$ Max Müller, ${ }^{2}{ }^{-B a b a k}$ N. Araabi, ${ }^{1}$ and $\odot$ Veronica Egger ${ }^{2}$ \\ ${ }^{1}$ School of Electrical and Computer Engineering, University of Tehran, 14395-515 Tehran, Iran, and ${ }^{2}$ Neurophysiology, Institute of Zoology, Universität \\ Regensburg, 93040 Regensburg, Germany
}

In the mammalian olfactory bulb, the inhibitory axonless granule cells (GCs) feature reciprocal synapses that interconnect them with the principal neurons of the bulb, mitral, and tufted cells. These synapses are located within large excitable spines that can generate local action potentials (APs) upon synaptic input ("spine spike"). Moreover, GCs can fire global APs that propagate throughout the dendrite. Strikingly, local postsynaptic $\mathrm{Ca}^{2+}$ entry summates mostly linearly with $\mathrm{Ca}^{2+}$ entry due to coincident global APs generated by glomerular stimulation, although some underlying conductances should be inactivated. We investigated this phenomenon by constructing a compartmental GC model to simulate the pairing of local and global signals as a function of their temporal separation $\Delta \mathrm{t}$. These simulations yield strongly sublinear summation of spine $\mathrm{Ca}^{2+}$ entry for the case of perfect coincidence $\Delta \mathrm{t}=0 \mathrm{~ms}$. Summation efficiency (SE) sharply rises for both positive and negative $\Delta t$. The SE reduction for coincident signals depends on the presence of voltage-gated Na ${ }^{+}$ channels in the spine head, while NMDARs are not essential. We experimentally validated the simulated SE in slices of juvenile rat brain (both sexes) by pairing two-photon uncaging of glutamate at spines and APs evoked by somatic current injection at various intervals $\Delta \mathrm{t}$ while imaging spine $\mathrm{Ca}^{2+}$ signals. Finally, the latencies of synaptically evoked global APs and EPSPs were found to correspond to $\Delta \mathrm{t} \approx 10$ $\mathrm{ms}$, explaining the observed approximately linear summation of synaptic local and global signals. Our results provide additional evidence for the existence of the GC spine spike.

Key words: coincidence detection; granule cell; NEURON model; olfactory bulb; spine spike; two-photon uncaging

\section{Significance Statement}

Here we investigate the interaction of local synaptic inputs and global activation of a neuron by a backpropagating action potential within a dendritic spine with respect to local $\mathrm{Ca}^{2+}$ signaling. Our system of interest, the reciprocal spine of the olfactory bulb granule cell, is known to feature a special processing mode, namely, a synaptically triggered action potential that is restricted to the spine head. Therefore, coincidence detection of local and global signals follows different rules than in more conventional synapses. We unravel these rules using both simulations and experiments and find that signals coincident within $\approx \pm 7 \mathrm{~ms}$ around $0 \mathrm{~ms}$ result in sublinear summation of $\mathrm{Ca}^{2+}$ entry because of synaptic activation of voltage-gated $\mathrm{Na}^{+}$channels within the spine.

\section{Introduction}

Within the dendrites of most types of neurons, backpropagating action potentials (bAPs) can influence the processing of incoming synaptic inputs. In neuron types where backpropagation is

\footnotetext{
Received July 13, 2018; revised Sept. 13, 2018; accepted 0ct. 9, 2018.

Author contributions:S.S.A. and V.E. wrote the first draft of the paper; S.S.A., M.M., and B.N.A. edited the paper; S.S.A., B.N.A., and V.E. designed research; S.S.A., M.M., and V.E. performed research; M.M. and V.E. analyzed data; V.E. wrote the paper.

This work was supported by German Ministry for Education and Research FKZ 01GQ1502 to V.E.; and I.R. Iran Cognitive Science and Technology Council to S.S.A. We thank Anne Pietryga-Krieger for technical assistance with the experiments; Arnd Roth for substantial advice on simulations; and Hamed Seyed-allaei and laboratory members for discussions.

The authors declare no competing financial interests.

Correspondence should be addressed to Veronica Egger at Veronica.Egger@ur.de.

https://doi.org/10.1523/JNEUROSCI.1798-18.2018

Copyright $\odot 2019$ the authors $\quad 0270-6474 / 19 / 390584-12 \$ 15.00 / 0$
}

supported by active conductances in the dendrite, bAPs provide a substantial depolarization of both the proximal and more distal dendritic membrane, resulting in opening of voltage-gated $\mathrm{Na}^{+}$, $\mathrm{K}^{+}$, and $\mathrm{Ca}^{2+}$ conductances $\left(\mathrm{Na}_{\mathrm{v}}, \mathrm{K}_{\mathrm{v}}, \mathrm{Ca}_{\mathrm{v}}\right)$ (Waters et al., 2005). Considerable backpropagation is reported from cortical and hippocampal pyramidal neuron dendrites (Stuart et al., 1997) and is particularly efficient in dendrites that release transmitter, including those of olfactory bulb (OB) mitral and granule cells (GCs) (Xiong and Chen, 2002; Egger et al., 2003).

If such bAPs now coincide with incoming synaptic input within a dendritic spine, supralinear summation of the respective $\mathrm{Ca}^{2+}$ signals has been observed in both excitatory pyramidal cells and inhibitory interneurons (e.g., Yuste and Denk, 1995; Koester and Sakmann, 1998; Camiré and Topolnik, 2014). This supralinearity has been linked to a lift of the $\mathrm{Mg}^{2+}$ block of the NMDAR 
A glomerular stimulation

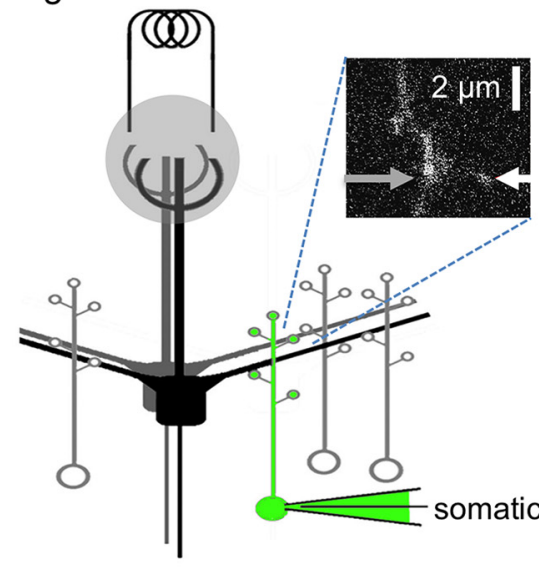

$100 \mu M O G B-1$
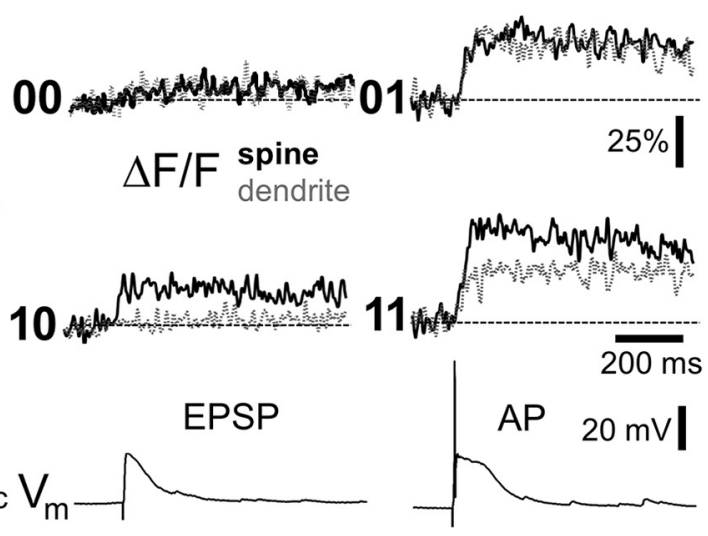

B

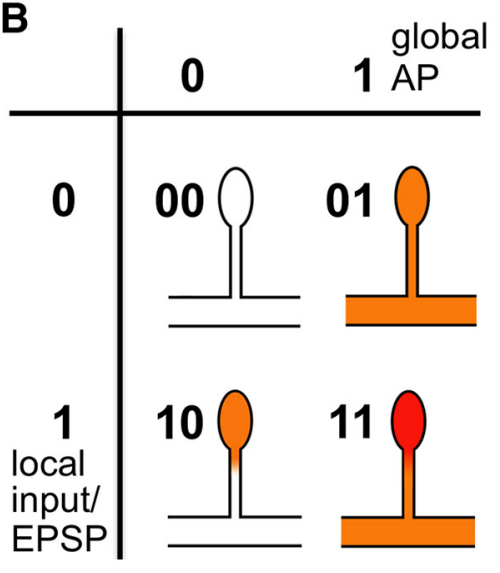

C

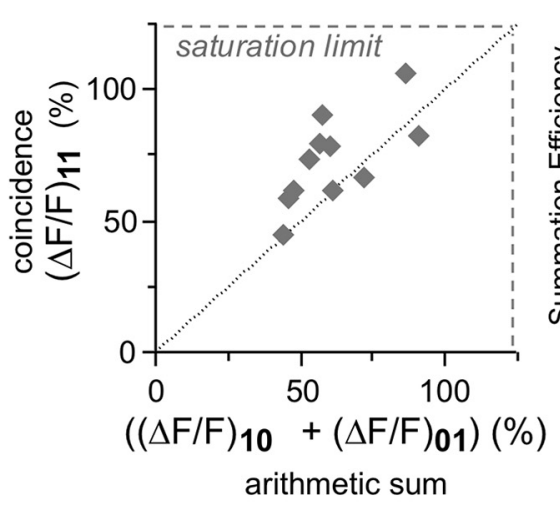

summation spine $(n=11)$

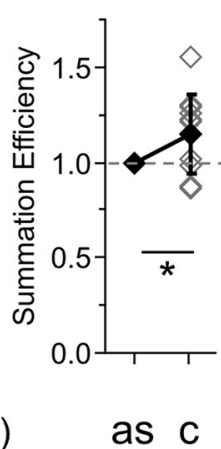

as $\mathrm{C}$

Figure 1. Summation of local synaptic inputs and global APs evoked by glomerular stimulation is mostly supralinear. $A$, Schematic depiction of experiment and example of individual experiment. Left, Stimulation of mitral cells via glomerular stimulation electrode, whole-cell recording of responses (EPSPs, APs) from GC, which is filled with $\mathrm{Ca}^{2+}$-sensitive dye via the patch pipette to allow for two-photon imaging of synaptic responses in individual spines. Right, bottom, $V_{m}$ recording from $\mathrm{GC}$ soma with similar stimulation strength: EPSP or AP. Middle and top right, Fluorescence transients (line scans) across spine and adjacent dendrite. Four types of responses: $\mathbf{0 0}$, no substantial $\Delta \mathrm{Ca}^{2+}$ in spine or dendrite; $\mathbf{1 0 ,} \Delta \mathrm{Ca}^{2+}$ limited to spine; $\mathbf{0 1}$, similar $\Delta \mathrm{Ca}^{2+}$ in spine and dendrite; 11 , larger $\Delta \mathrm{Ca}^{2+}$ in spine than in dendrite, $\Delta \mathrm{Ca}^{2+}$ in dendrite similar to 01 . Middle, Two-photon scan of imaged spine and dendrite. $\boldsymbol{B}$, The matrix of possible spine states with respect to $\Delta \mathrm{Ca}^{2+}$ as inferred from the responses: $\mathbf{0 0}$, no local input, no AP; $\mathbf{1 0}$, local synaptic input to spine head; $\mathbf{0 1}$, global AP without local activation; $\mathbf{1 1}$, coincident global AP and local activation. The associated $\Delta \mathrm{Ca}^{2+}$ is depicted as red intensity. C, Left, Cumulative scatter plot of $n=11$ experiments. $x$ axis represents arithmetic sum of spine $\Delta \mathrm{F} / \mathrm{F}$ amplitudes for AP and local input (10 $+\mathbf{0 1}$ ).

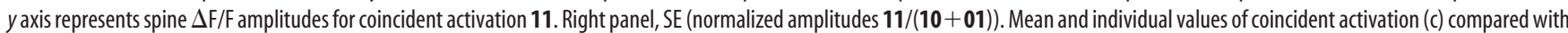
arithmetic summation (as). Error bars indicate SD. ${ }^{*} p<0.05$. A, Left, Scheme modified from Egger et al. (2005). Right, Modified from Egger (2008). C, Left, Reanalyzed from Egger (2008) with additional data from two more spines.

by the bAP, facilitating $\mathrm{Ca}^{2+}$ entry (e.g., Schiller et al., 1998; Yuste et al., 1999; Nevian and Sakmann, 2004), which could be further enhanced by a supralinearity in $V_{\mathrm{m}}$ that relies on additional $\mathrm{Na}_{\mathrm{v}}$ activation during the coincidence of bAP and EPSP (Stuart and Häusser, 2001) or on predepolarization by AMPARs due to electrical compartmentalization of the spine head (Grunditz et al., 2008). Overall, the degree of $\mathrm{Ca}^{2+}$ signal supralinearity was found to strongly depend on the temporal sequence of EPSP and bAP.

In $\mathrm{OB}$ GC spines, we have consistently observed that local synaptic $\mathrm{Ca}^{2+}$ signals summate linearly or even supralinearly with action potential (AP)-mediated global $\mathrm{Ca}^{2+}$ signals (Fig. 1) (Egger, 2008). Yet this observation is surprising in view of our recent finding of a "spine spike" within the reciprocal GC spines, where boosting by a high spine neck resistance allows AMPARmediated depolarization to elicit a regular $\mathrm{Na}^{+}-\mathrm{AP}$ that is restricted to the spine head and causes $\mathrm{Ca}^{2+}$ entry via highvoltage-activated $\mathrm{Ca}^{2+}$ channels (HVACCs) (Bywalez et al., 2015). Moreover, NMDARs at this synapse are already relieved of their $\mathrm{Mg}^{2+}$ block by the AMPAR-mediated depolarization and contribute substantially to postsynaptic $\mathrm{Ca}^{2+}$ transients (Egger et al., 2005; Bywalez et al., 2015).

Thus, several voltage-dependent conductances are shared between the global AP and the spine spike; therefore, coincident signals would be expected to summate sublinearly. However, this inference is based on the assumption that the two APs perfectly coincide within the spine head. We hypothesized that sublinear summation was obscured by a certain temporal offset between the two spikes. Then what would be the minimal temporal offset required to obtain linear summation? How about the situation where the global AP precedes a local synaptic input (anti-Hebbian pairing)?

To solve these issues, we first turned to simulations of the local $V_{\mathrm{m}}$ and $\Delta\left[\mathrm{Ca}^{2+}\right]_{i}$ in the spine because (1) experimental detection of $V_{\mathrm{m}}$ in the spine is not yet feasible; and (2) the various entangled voltage-dependent mechanisms are difficult to dissociate in experiments. The simulations were constrained by a substantial body of previous work on endogenous $\mathrm{Ca}^{2+}$ dynamics in GC spines (Egger and Stroh, 2009), basic models of the spine spike (Bywalez et al., 2015) and of backpropagating APs in GC den- 
drites (Ona-Jodar et al., 2017), somatic voltage recordings of EPSPs and APs, and also $\mathrm{GC} \mathrm{Ca}^{2+}$ signals in spines and dendrites following local synaptic inputs and global APs (Egger et al., 2003, 2005; Egger, 2008; Stroh et al., 2012). In addition, we could draw on recordings of $\mathrm{GC} \mathrm{Ca}^{2+}$ currents to further constrain $\mathrm{Ca}^{2+}$ channel kinetics.

To test the predictive power of these simulations, we performed another set of $\mathrm{Ca}^{2+}$ imaging experiments where twophoton uncaging (TPU) of glutamate at a single spine was paired with somatically evoked APs at a set of pairing intervals, namely, near-simultaneous activation and a Hebbian and anti-Hebbian sequence with intervals of $10 \mathrm{~ms}$, respectively.

\section{Materials and Methods}

Modeling concept. Our modeling approach builds on experiences gained with a previous NEURON model (Bywalez et al., 2015, their Supplemental data). The current model is constrained by a larger set of experimental data and did not involve a large-scale parameter scan. The model was used to predict summation efficiency (SE) of local and global signals in the spine head and then validated by a set of pairing experiments.

The GC model is constructed by connecting a series of compartments for the soma, one dendritic branch, and one spine consisting of neck and spine head. Figure $2 A$ illustrates the main incorporated ion conductances for $\mathrm{Ca}^{2+}$, $\mathrm{Na}^{+}$, and $\mathrm{K}^{+}$and sequestration mechanisms for $\mathrm{Ca}^{2+}$. The intracellular $\mathrm{Ca}^{2+}$ dynamics is governed by radial and longitudinal diffusion, extrusion, and the endogenous buffering capacity, with the dye OGB-1 included as an exogenous buffering capacity. To render simulations amenable to direct comparison with imaging data, the momentary intracellular concentration $\left[\mathrm{Ca}^{2+}\right]_{i}(\mathrm{t})$ is then translated to fluorescence changes $(\Delta \mathrm{F} / \mathrm{F})(\mathrm{t})$ using the mapping described further below. The model is then implemented with NEURON (Release 7.4) (Carnevale and Hines, 2006) along with Python (Hines et al., 2009). The source code for the model can be found at http://senselab.med.yale.edu/ModelDB as model entry 244687.

Figure $2 B$ shows the simulations of the two individual stimuli. Local synaptic inputs are mimicked by a glutamate pulse of $1 \mathrm{~mm}$ concentration for $3 \mathrm{~ms}$ (Bywalez et al., 2015). Global somatically evoked APs (sAPs) are generated via a somatic current step of $1 \mathrm{nA}$ for $3 \mathrm{~ms}$.

The model replicates the following kinetics and dynamics based on previous experimental results (all obtained at room temperature $21^{\circ} \mathrm{C}-$ $22^{\circ} \mathrm{C}$, model temperature $22^{\circ} \mathrm{C}$ ):

- somatic $V_{\mathrm{m}}$ : resting $V_{\mathrm{m}}-85 \mathrm{mV}$ and kinetics and amplitude of EPSP and sAP (Egger et al., 2003, 2005);

- proper electrical isolation of the spine: local $\mathrm{Na}^{+}-\mathrm{AP}$ following AMPAR-mediated depolarization, large spine neck resistance (Bywalez et al., 2015);

- $\mathrm{Ca}^{2+}$ dynamics: amount of absolute $\mathrm{Ca}^{2+}$ entry during sAP in the spine and the parent dendrite, endogenous buffering capacity, and extrusion rate (Egger and Stroh, 2009);

- kinetics and amplitude of $(\Delta \mathrm{F} / \mathrm{F})_{\mathrm{syn}}$ and $(\Delta \mathrm{F} / \mathrm{F})_{\mathrm{sAP}}$ in the spine and in the adjacent dendrite (Egger et al., 2003, 2005);

- relative contributions of $\mathrm{Ca}^{2+}$ sources (NMDAR, T-type CC, HVACC) to $(\Delta \mathrm{F} / \mathrm{F})_{\text {sAP }}$ and $(\Delta \mathrm{F} / \mathrm{F})_{\text {syn }}$ (Egger et al., 2003, 2005; Bywalez et al., 2015); dendrite.
B

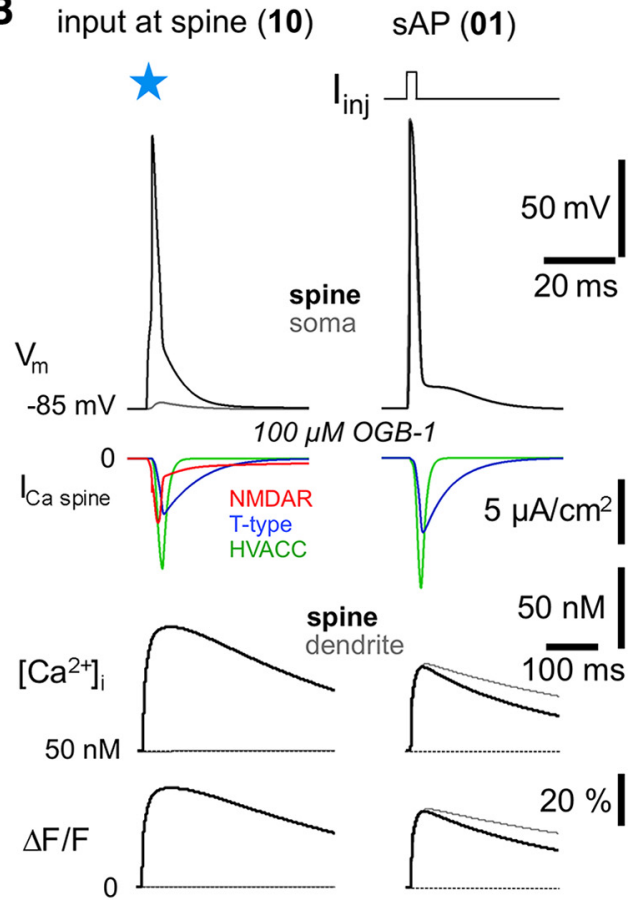

Figure 2. Simulation methods 1 . NEURON model and simulation of individual events. $A$, Schematic depiction of essential S. Left, The synaptic input mimicked by pulse of glutamate Right, SAP. Top, Stimulus and spine and somatic membran also not to the soma (gray trace), whereas $V_{m}(t)$ is identical in spine and soma for the sAP; therefore, the somatic response is hidden by the spine response. Middle, Associated Ca ${ }^{2+}$ currents in spine head. Bottom, Changes in intracellular $\mathrm{Ca}^{2+}$ and associated fluorescence transients in spine and adjacent dendrite (gray trace). For the spine spike, there is no detectable transient in the

- deactivation kinetics of high- and low-voltage-activated $\mathrm{Ca}^{2+}$ channels in GCs as measured at the soma.

The model does not attempt to fully represent current knowledge on GC electrical and $\mathrm{Ca}^{2+}$ signaling but only contains those elements with sufficient experimental evidence and plausible involvement in coincident signaling. For example, it does not contain various subtypes of $\mathrm{K}_{\mathrm{v}}$ channels, metabotropic glutamate receptors, transient receptor potential canonical (TRPC) channels, and $\mathrm{Ca}^{2+}$ release from internal stores.

Detailed description of the model. Passive properties of the cylindrical compartments are $C_{\mathrm{m}}=1 \mu \mathrm{F} / \mathrm{cm}^{2}, R_{\mathrm{m}}=5000 \Omega \mathrm{cm}^{2}, R_{\mathrm{i}}=200 \Omega \mathrm{cm}$. The dimensions of the somatic compartment are length $\mathrm{L}=10 \mu \mathrm{m}$ and diameter $\mathrm{d}=10 \mu \mathrm{m}$. The total length of the dendrite is $260 \mu \mathrm{m}$, consisting of 26 sections, which taper from the initial diameter of $d=2.35 \mu \mathrm{m}$ to $\mathrm{d}=1.7 \mu \mathrm{m}$ over the first $100 \mu \mathrm{m}$, where the first spine is placed, and then continue until $\mathrm{d}=1.2 \mu \mathrm{m}$ for the last dendritic section, as in Ona-Jodar et al. (2017).

The dimensions of the spine head compartment are $\mathrm{L}=1 \mu \mathrm{m}, \mathrm{d}=1$ $\mu \mathrm{m}$ and of the neck $\mathrm{L}=2.5 \mu \mathrm{m}, \mathrm{d}=0.3 \mu \mathrm{m}$ (Woolf et al., 1991). Proper isolation of the spine head from the parent dendrite is ensured by a different value of the axial resistance within the spine neck section, $R_{\mathrm{i} \_ \text {Neck }}=4.9 \mathrm{k} \Omega \mathrm{cm}$, which yields a neck resistance value within the previously predicted range: $R_{\text {Neck }}=R_{\mathrm{i} \_ \text {Neck }} \cdot \mathrm{L} / \mathrm{A}=1.7 \mathrm{G} \Omega(\mathrm{A}=\pi$ $(\mathrm{d} / 2)^{2}$ (Bywalez et al., 2015).

Transmembranal mechanisms for the dendrite and spine include pumps for $\mathrm{Ca}^{2+}$ with a density of $2 \mathrm{e}^{-11} \mathrm{~mol} / \mathrm{cm}^{2}$, Hodgkin-Huxley models of $\mathrm{Na}^{+}$and $\mathrm{K}^{+}$channels (Migliore et al., 1995), and T-type $\mathrm{Ca}^{2+}$ channels and HVACCs (Hemond et al., 2008). We chose an axonal $\mathrm{Na}^{+}$ channel model, with similar density in spine and dendrite, based on (Nunes and Kuner, 2018). The total conductances are listed in Table 1.

The AMPARs and NMDARs of the spine are represented by Markov models with parameter settings as in Lester and Jahr (1992). A fraction of $4.25 \%$ of the NMDAR total conductance is assigned to $\mathrm{Ca}^{2+}$ (Table 1 ) to 
Table 1. Model parameters: conductances and buffer properties ${ }^{a}$

\begin{tabular}{|c|c|c|}
\hline Parameter, location & Mechanism & Value \\
\hline$g_{\mathrm{Nav}}$ spine and dendrite & $\mathrm{Na}_{\mathrm{v}}$ conductance density & $0.5 \mathrm{~S} / \mathrm{cm}^{2}$ \\
\hline $\mathrm{g}_{\mathrm{Kv}}$ spine and dendrite & $\mathrm{K}_{\mathrm{v}}$ conductance density & $0.01 \mathrm{~S} / \mathrm{cm}^{2}$ \\
\hline$g_{\text {Ttype }}$ spine & T-type $\mathrm{Ca}^{2+}$ conductance density & $0.00015 \mathrm{~S} / \mathrm{cm}^{2}$ \\
\hline $\mathrm{g}_{\text {Ttype }}$ dendrite & T-type $\mathrm{Ca}^{2+}$ conductance density & $0.0003 \mathrm{~S} / \mathrm{cm}^{2}$ \\
\hline$g_{\text {HVACC }}$ spine & $\mathrm{HVACa}^{2+}$ conductance density & $0.0004 \mathrm{~S} / \mathrm{cm}^{2}$ \\
\hline$g_{\text {HVACC }}$ dendrite & $\mathrm{HVACa}^{2+}$ conductance density & $0.0005 \mathrm{~S} / \mathrm{cm}^{2}$ \\
\hline$g_{\text {AMPA }}$ & Synaptic AMPA receptor conductance & $2000 \mathrm{pS}$ \\
\hline$g_{\text {NMDA }}($ total) & $\begin{array}{l}\text { Synaptic NMDA receptor conductance } \\
\text { (all ions) }\end{array}$ & $400 \mathrm{pS}$ \\
\hline$g_{\mathrm{NMDA}}\left(\mathrm{Ca}^{2+}\right)$ & $\begin{array}{l}\text { Synaptic NMDA receptor } \mathrm{Ca}^{2+} \\
\text { conductance }\end{array}$ & $17 \mathrm{pS}$ \\
\hline $\mathrm{K}_{\mathrm{on}}$ endogenous buffer & & $1000{\text { (mм ms })^{-1}}^{-1}$ \\
\hline $\begin{array}{l}K_{\text {on }} \text { exogenous buffer } \\
K_{\text {off }} \text { endogenous buffer }\end{array}$ & Dye (0GB-1) & $\begin{array}{l}1000 \text { (mM ms}^{-1} \\
1 \mathrm{~ms}^{-1}\end{array}$ \\
\hline $\mathrm{K}_{\text {off }}$ exogenous buffer & Dye (0GB-1) & $0.2 \mathrm{~ms}^{-1}$ \\
\hline
\end{tabular}

${ }^{a}$ S, Siemens.

match the experimental results, which lies within the same order of magnitude as in the previous model (Bywalez et al., 2015).

Radial and longitudinal diffusion are modeled exactly as previously described (Bywalez et al., 2015, their Fig. 5A and supplemental procedures). Free and buffered $\mathrm{Ca}^{2+}$ ions are diffusing within the cell, with a diffusion coefficient of $0.6 \mu \mathrm{m}^{2} / \mathrm{ms}$. Endogenous and exogenous buffers (dye) diffuse with similar rates (diffusion coefficients for buffer and Cabuffer complex are both $0.015 \mu \mathrm{m}^{2} / \mathrm{ms}$ ). The endogenous buffer is defined as the fast buffer type from Markram et al. (1998) with a concentration of $120 \mu \mathrm{M}$ and rates $\mathrm{k}_{\mathrm{on}}$, $\mathrm{k}_{\text {off }}$ that satisfy $\kappa_{\mathrm{E}}=100$ (Egger and Stroh, 2009), while the exogenous buffer concentration and dissociation factor replicate those of OGB-1 in the experiment (100 $\mu \mathrm{M}$ and $K_{\mathrm{d}}=200 \mathrm{~nm}$ ). The detailed buffer settings are listed in Table 1.

Robustness tests. To evaluate the robustness of the model with respect to the absolute values of SE and the relation between SE and pairing interval, uniform random variations were applied to a set of parameter values (Sobol, 2001) that were not strongly constrained by previous experiments and/or are playing a dominant role for electrical compartmentalization. The selected parameters were the individual spine head conductances for $\mathrm{Ca}^{2+}$ (via HVA and T-type $\mathrm{Ca}^{2+}$ channels and the NMDAR, $\left.g_{\text {Ttype }}, g_{\text {HVACC }}, g_{\text {Ca_NMDA }}\right)$, the coupled spine head conductances of $\mathrm{Na}_{\mathrm{v}}$ and $\mathrm{K}_{\mathrm{v}}\left(\mathrm{g}_{\mathrm{Nav} / \mathrm{Kv}}\right)$, the spine head AMPAR conductance $\mathrm{g}_{\mathrm{AMPA}}$, and the neck resistance $R_{\mathrm{Neck}}$ (via proportional changes in axial neck resistance $R_{\mathrm{i} \_ \text {Neck }}$, see above). The variation amplitude was chosen randomly between $50 \%$ and $200 \%$ of the nominal parameter value, and the random variations were repeated 30 times for each parameter. If a given random parameter variation failed to produce a full-blown spine spike (such as the one shown in Fig. 2B, left column), SE was not evaluated. Values too small for spine spike generation occurred for $\mathrm{g}_{\mathrm{Nav} / \mathrm{Kv}}$, $\mathrm{g}_{\mathrm{AMPA}}$, and $R_{\mathrm{Neck}}$.

Properties of GC C $a_{v}$ channels. GCs have been reported to feature substantial amounts of both HVA and LVA (T-type) $\mathrm{Ca}^{2+}$ conductances (Egger et al., 2003; Isaacson and Vitten, 2003; Pinato and Midtgaard, 2003). Our HVA and T-type $\mathrm{Ca}_{\mathrm{v}}$ models are based on Hemond et al. (2008). However, we noted that the deactivation kinetics of these models were too slow $\left(\tau_{1 / 2 \text { deact }}=16 \mathrm{~ms}\right.$ for both $)$, given that, for example, a blockade of T-type channels did not affect the rise time of AP-evoked $\mathrm{Ca}^{2+}$ transients $(\Delta \mathrm{F} / \mathrm{F})_{\mathrm{sAP}}$ in GC dendrites and spines of $\sim 15 \mathrm{~ms}(100$ $\mu \mathrm{M}$ OGB-1) (Egger et al., 2003) and that deactivation of T-type channels also appears fast in the examples shown in Isaacson and Vitten (2003). To further constrain $\mathrm{Ca}_{\mathrm{v}}$ deactivation kinetics, we analyzed a small set of own GC voltage-clamp experiments at room temperature where GCs ( $n=4$ cells) were depolarized from a holding potential of $V_{\mathrm{m}}=-70 \mathrm{mV}$ in $\Delta \mathrm{V}=10 \mathrm{mV}$ steps up to $0 \mathrm{mV}$ for either 3 or $200 \mathrm{~ms}$, then returning to $-70 \mathrm{mV}$, and $\mathrm{Ca}^{2+}$ currents were isolated via pharmacological blockade of $\mathrm{Na}_{\mathrm{v}}$ and $\mathrm{K}_{\mathrm{v}}$ channels and a CsMeSO${ }_{4}$-based internal solution. Series resistance was compensated for, and leak subtraction was performed. If we assume that T-type channel activation is weak during the short depo- larizing pulse (at room temperature) (Blackmer et al., 2009), these experiments yield upper limits for the deactivation half-time for HVACCs of $\tau_{1 / 2 \text { _deact }}=2.3 \pm 0.6 \mathrm{~ms}$ and for T-type channels of $\tau_{1 / 2 \text { _deact }}=8.1 \pm$ $1.4 \mathrm{~ms}$. While these values do not necessarily reflect channel kinetics within the GC spines (which might be difficult to clamp, especially for the 3 ms depolarization) (Beaulieu-Laroche and Harnett, 2018), our previous study on dendritic $\mathrm{Ca}^{2+}$ signals mediated by backpropagating APs implies that HVA and T-type CCs are likely to be distributed across spines and dendrites with similar densities and properties (Egger et al., 2003).

Conversion of simulated $\Delta \mathrm{Ca}^{2+}$ into $\Delta F / F$ signals. First, we aimed to estimate the regimen within which experimental $\Delta \mathrm{F} / \mathrm{F}$ data can be used as a reliable readout for changes in $\left[\mathrm{Ca}^{2+}\right]_{i}$ at a dye concentration of $100 \mu \mathrm{M}$ OGB-1, including the larger range of $\Delta \mathrm{F} / \mathrm{F}$ in response to summating inputs. We analyzed $\Delta \mathrm{F} / \mathrm{F}$ responses to saturating trains of APs at $50 \mathrm{~Hz}$ (from Egger and Stroh, 2009) by comparing these $(\Delta \mathrm{F} / \mathrm{F})_{50 \mathrm{~Hz}}$ responses with arithmetically summated responses to single somatically evoked APs $(\Delta \mathrm{F} / \mathrm{F})_{s A P}$ recorded at the same location (Fig. $3 A$ ). These fictive linear responses were generated by first fitting the measured $(\Delta \mathrm{F} / \mathrm{F})_{\mathrm{sAP}}$ by an exponential $(\Delta \mathrm{F} / \mathrm{F})_{\mathrm{sAP}}(\mathrm{t})=\mathrm{A} \cdot \exp \left(-\mathrm{t} /\left(\tau_{1 / 2} \cdot \ln 2\right)\right.$, with $\tau_{1 / 2}$ denoting the half-duration of $(\Delta \mathrm{F} / \mathrm{F})_{\mathrm{sAP}}$ and $\mathrm{A}$ the maximal amplitude of $(\Delta \mathrm{F} /$ $\mathrm{F})_{\mathrm{sAP}}$. Then these fits were summated at intervals of $20 \mathrm{~ms}$, and the resulting fictive linear response was overlaid with $(\Delta \mathrm{F} / \mathrm{F})_{50 \mathrm{~Hz}}$. Responses to trains roughly matched with the fictive linear response on average up to $123 \pm 23 \% \Delta \mathrm{F} / \mathrm{F}$ and strongly deviated from the fictive response for larger responses ( $n=11$ locations in 5 GCs). Therefore, experiments with $\Delta \mathrm{F} / \mathrm{F}$ responses $>125 \%$ were removed from the preexisting dataset (Fig. 1C) and also rejected from our new dataset obtained with TPU (see below). Our simulated summated $\Delta \mathrm{F} / \mathrm{F}$ signals do not overshoot this saturation limit $(\Delta \mathrm{F} / \mathrm{F}$ values for individual signals sAP $=30 \%$ and spine spike $=40 \% \Delta \mathrm{F} / \mathrm{F}$, Fig. $2 B$; maximal summated signals thus $<90 \% \Delta \mathrm{F} / \mathrm{F}$; for results, see Fig. $4 B, C$ ).

Because $\Delta \mathrm{F} / \mathrm{F}$ does not directly report $\Delta\left[\mathrm{Ca}^{2+}\right]_{i}$ but rather reflects changes in the concentration of the complex [Ca-dye] and because the affinity of OGB-1 is high $\left(K_{\mathrm{d}} \approx 200 \mathrm{nM}\right)$, we next accounted for buffer saturation already below the limit of $125 \% \Delta \mathrm{F} / \mathrm{F}$ by simulating the increase in [Ca-dye] during the AP train (Fig. $3 B$ ). To convert simulated changes in $\left[\mathrm{Ca}^{2+}\right]_{i}$ in the presence of $100 \mu \mathrm{M}$ OGB-1 into fluorescence changes within the regimen of up to $125 \% \Delta \mathrm{F} / \mathrm{F}$, we plotted the preexisting data on absolute $\mathrm{Ca}^{2+}$ changes for the first sAP and the associated $\Delta \mathrm{F} / \mathrm{F}$ changes in spines at this dye concentration and extrapolated these data to the saturation limit established above, while correcting the $\Delta \mathrm{F} / \mathrm{F}$ values for later APs in the train for the buffer saturation (Fig. $3 C$; for first $\operatorname{AP}(\Delta \mathrm{F} / \mathrm{F})_{\mathrm{sAP}}=30 \%, \Delta\left[\mathrm{Ca}^{2+}\right]_{i}=45 \mathrm{nM}$, basal free $\left[\mathrm{Ca}^{2+}\right]_{0}=50 \mathrm{nM}$ from Egger and Stroh (2009). The correction shows as negative deviation of the conversion curve from a strictly linear increase. The data points were fitted with a sigmoidal function; the maximal average $\Delta \mathrm{F} / \mathrm{F}$ value was estimated as $220 \%$ from Egger and Stroh (2009) based on the estimate of $\mathrm{f}_{\max }$ given in Maravall et al. (2000, their Eq. 11).

Experiments: electrophysiology, TPU of glutamate, and pairing with sAP. Preparation of acute OB brain slices from juvenile rats of either sex (postnatal days 11-17, Wistar) was performed in accordance with the rules laid down by the EC Council Directive (86/89/ECC) and German animal welfare legislation. Recordings from GCs were achieved at room temperature, as described previously (Egger et al., 2003). TPU of glutamate and simultaneous two-photon $\mathrm{Ca}^{2+}$ imaging at GC spines were performed as described by Bywalez et al. (2015), with $100 \mu \mathrm{M}$ of the $\mathrm{Ca}^{2+}$-indicator OGB-1 (Invitrogen) and $60 \mu \mathrm{M}$ of the red fluorescent dye AlexaFluor-594 (Invitrogen) added to the internal solution (in $\mathrm{mm}$ as follows: $130 \mathrm{~K}$-methylsulfate, 10 HEPES, $4 \mathrm{MgCl}_{2}, 2.5 \mathrm{Na}_{2} \mathrm{ATP}, 0.4$ NaGTP, 10 Na-phosphocreatine, 2 ascorbate, pH 7.3). and 1 mM DNIglutamate (Femtonics) to the bath ACSF (in mM as follows: $125 \mathrm{NaCl}, 26$ $\mathrm{NaHCO}_{3}, 1.25 \mathrm{NaH}_{2} \mathrm{PO}_{4}, 20$ glucose, $2.5 \mathrm{KCl}, 1 \mathrm{MgCl}_{2}, 2 \mathrm{CaCl}_{2}$ ).

A step current injection was applied $(1 \mathrm{~ms}, 1 \mathrm{nA})$ via the patch pipette to evoke sAPs; TPU was performed within a time window of $0.5-1 \mathrm{~ms}$ at a wavelength of $750 \mathrm{~nm}$ and a power of $\sim 15 \mathrm{~mW}$ at the uncaging site (Bywalez et al., 2015), whereas the two-photon imaging laser was set to an excitation wavelength of $835 \mathrm{~nm}$ and a power of $<5 \mathrm{~mW}$. Five different protocols (TPU alone, sAP alone, pairing of TPU and sAP with an inter- 
A
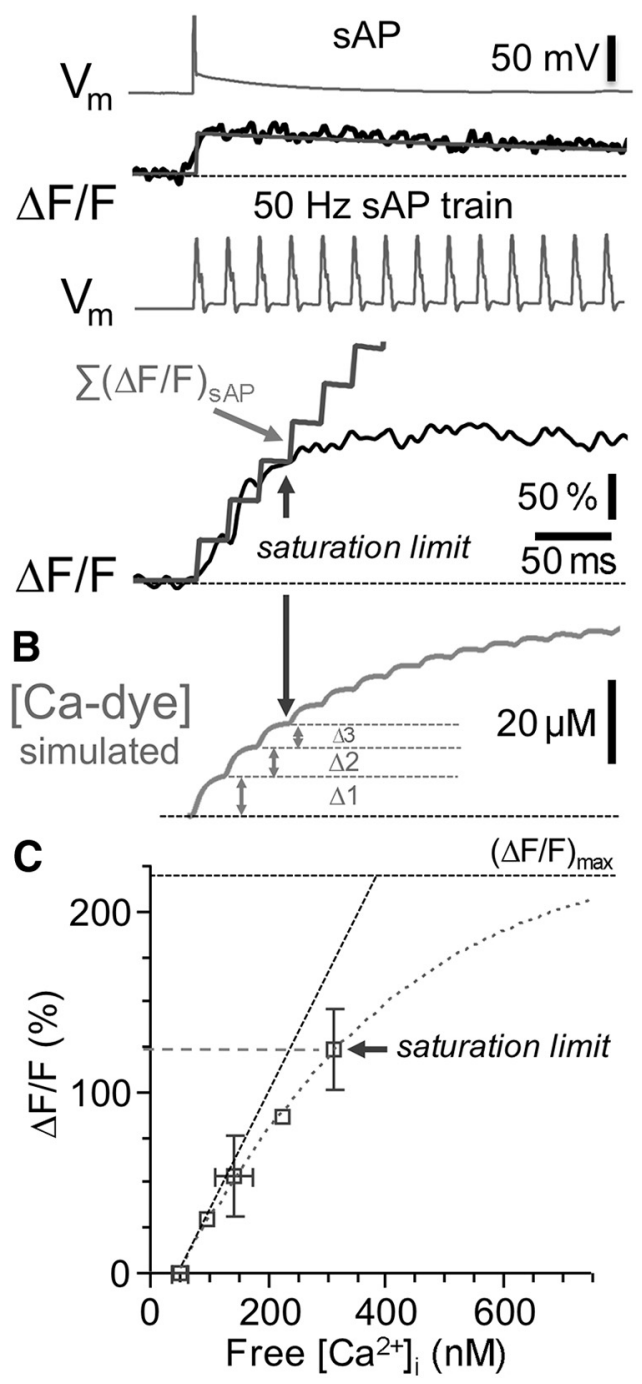

Figure 3. Simulation methods 2. Conversion of $\mathrm{Ca}^{2+}$ transients into fluorescence changes under our experimental conditions (100 $\mu \mathrm{m}$ OGB-1). $A$, Example analysis of $\Delta \mathrm{F} / \mathrm{F}$ responses to single somatically evoked APs and AP trains $(50 \mathrm{~Hz})$ to estimate the saturation limit for the reliable detection of absolute $\Delta \mathrm{Ca}^{2+}$ changes based on $\Delta \mathrm{F} / \mathrm{F}$. $(\Delta \mathrm{F} / \mathrm{F})_{s A P}$ was fitted with a single exponential; the fit was then linearly summated and compared with $(\Delta \mathrm{F} / \mathrm{F})_{5 \mathrm{OHz}}$. The saturation limit was chosen as the $\Delta \mathrm{F} / \mathrm{F}$ value above which the recorded signal would strongly deviate from the summated fit. $\boldsymbol{B}$, Simulation of concentration change of the $\mathrm{Ca}^{2+}$-dye complex during AP train based on $K_{d}=200 \mathrm{~nm}$. The reduced increase, and therewith the reduction in additional $\Delta \mathrm{F} / \mathrm{F}$ in response to later $\mathrm{APs}$, was then applied to adjust the conversion in $\mathrm{C}$ from a linear increase to a sublinear increase. $C$, Lookup table for conversion of $\Delta \mathrm{Ca}^{2+}$ into $\Delta \mathrm{F} / \mathrm{F}$, used up to the mean saturation limit of $125 \%$ derived from $\boldsymbol{A}$.

val between the respective stimulus onsets of $\Delta t=-10,0$, and $+10 \mathrm{~ms}$ ) were interleaved at random, with interstimulation intervals $\geq 60 \mathrm{~s}$. In most experiments, 3 individual stimulations were recorded per protocol and the responses were averaged. A larger number of stimulations, as would be desirable to fully detect the variance across responses for a given protocol ( $n \geq 5$ per protocol, as established in the course of our previous studies) (Egger et al., 2005; Bywalez et al., 2015) and to perform pharmacological manipulations, often caused an increase of the basal fluorescence signal $\mathrm{F}_{0}$ and therewith a degradation of $\Delta \mathrm{F} / \mathrm{F}$.

The neck length of spines was estimated as described previously (Bywalez et al., 2015, supplemental experimental procedure).

Reanalysis of synaptic dataset on coincidence detection. The dataset based on synaptic inputs via glomerular stimulation was corrected for contributions from low-threshold $\mathrm{Ca}^{2+}$ spikes, which occurred in some of these experiments because of the stimulation of multiple synaptic inputs (LTS, first described by Egger et al., 2005, correction for 6 of 11 spines in the dataset). This procedure was necessary to isolate the summation of purely local signals and APs because, otherwise, the global activation of T-type channels during the synaptically evoked LTS would count toward both the $\mathbf{1 0}$ and the $\mathbf{0 1} \Delta \mathrm{F} / \mathrm{F}$ signals; thus, the SE would be underestimated compared with the SE of purely local signals, which we are investigating in the TPU dataset in this study. The criterion for the presence of an LTS in the $\mathbf{1 0}$ case was a substantial dendritic $\Delta \mathrm{F} / \mathrm{F}>10 \%$, which was never observed for purely local spine activation during spontaneous inputs or TPU-evoked local activation (Egger et al., 2003; Bywalez et al., 2015). For these spines, we subtracted two-thirds of the dendritic $(\Delta \mathrm{F} / \mathrm{F})_{\mathrm{LTS}}$ from the spine's $(\Delta \mathrm{F} / \mathrm{F})_{\text {syn }}$. This estimate of extra T-type channel contribution is based on our previous findings that, on average, $(\Delta \mathrm{F} / \mathrm{F})_{\mathrm{LTS}}$ is identical across spine and dendrite and has a mean value of $\sim 25 \%$, and purely local synaptic signals are entirely localized to the spine head, with an average contribution of T-type channels on the order of 0.29 of the total average $40 \%(\Delta \mathrm{F} / \mathrm{F})_{\text {syn }}$ (Egger et al., 2005), so there is $\sim 10 \% \Delta \mathrm{F} / \mathrm{F}$ contributed from the local spine spike, which leaves $15 \%$ or approximately two-thirds of $(\Delta \mathrm{F} / \mathrm{F})$ LTS for the extra LTS contribution.

Experimental design and statistical analyses. All mean values are given \pm SD. Comparisons between datasets are always made using nonparametric directional tests, either the Wilcoxon test for paired samples (e.g., for comparing responses to different stimulation protocols in the same spine) or the Mann-Whitney test for nonpaired samples (e.g., for comparing $\mathrm{Ca}^{2+}$ signals evoked by synaptic stimulation and uncaging in different spines).

\section{Results}

Summation of synaptic and global AP signals in response to glomerular stimulation

We reinvestigated synaptic GC spine $\mathrm{Ca}^{2+}$ transients in response to glomerular stimulation of mitral and tufted cells (MTCs) at the threshold between EPSP and global AP (Fig. 1, part of dataset previously published by Egger, 2008). In the glomerular stimulation paradigm, an extracellular electrode is placed within a glomerulus to stimulate the highly excitable MTC apical dendrites (Fig. 1A), ensuring a specific activation of MTC inputs to GCs (Schoppa et al., 1998).

Because of the stochastic nature of synaptic transmission at this synapse with an average release probability of 0.5 (Egger et al., 2005), we encountered four types of responses in a subset of active spines, 2 each for EPSP and AP (Fig. $1 A, B$ ): (1) EPSP 00, no $\Delta \mathrm{Ca}^{2+}$ at all, corresponding to a failure; (2) EPSP $10, \Delta \mathrm{Ca}^{2+}$ in the spine head but not in the dendrite, reporting local synaptic input (see also Egger et al., 2005); (3) AP 01, similar $\Delta \mathrm{Ca}^{2+}$ in spine and dendrite reporting a globally propagating AP (see also Egger et al., 2003); and (4) AP 11, substantially larger $\Delta \mathrm{Ca}^{2+}$ in spine than in dendrite and $\Delta \mathrm{Ca}^{2+}$ in dendrite similar to the 01 case, reporting the coincidence between local input and global AP in the spine.

To precisely detect the degree of summation of synaptic inputs and global AP signals in these coincidence experiments, we reanalyzed these data and dismissed experiments with large $(\Delta \mathrm{F} / \mathrm{F})$ signals where the $\mathrm{Ca}^{2+}$-sensitive dye could have been overly saturated (for establishment of quasi-linear regimen, see Materials and Methods). We also integrated additional experiments that were not yet available in the previous study and corrected the dataset for contributions from low-threshold $\mathrm{Ca}^{2+}$ spikes (Egger et al., 2005) to isolate the summation of purely local signals and global APs (see Materials and Methods for rationale and correction procedure).

The cumulative result is shown in Figure $1 C(n=11$ spines, with a mean distance from the soma of $65 \pm 49 \mu \mathrm{m})$, with the 

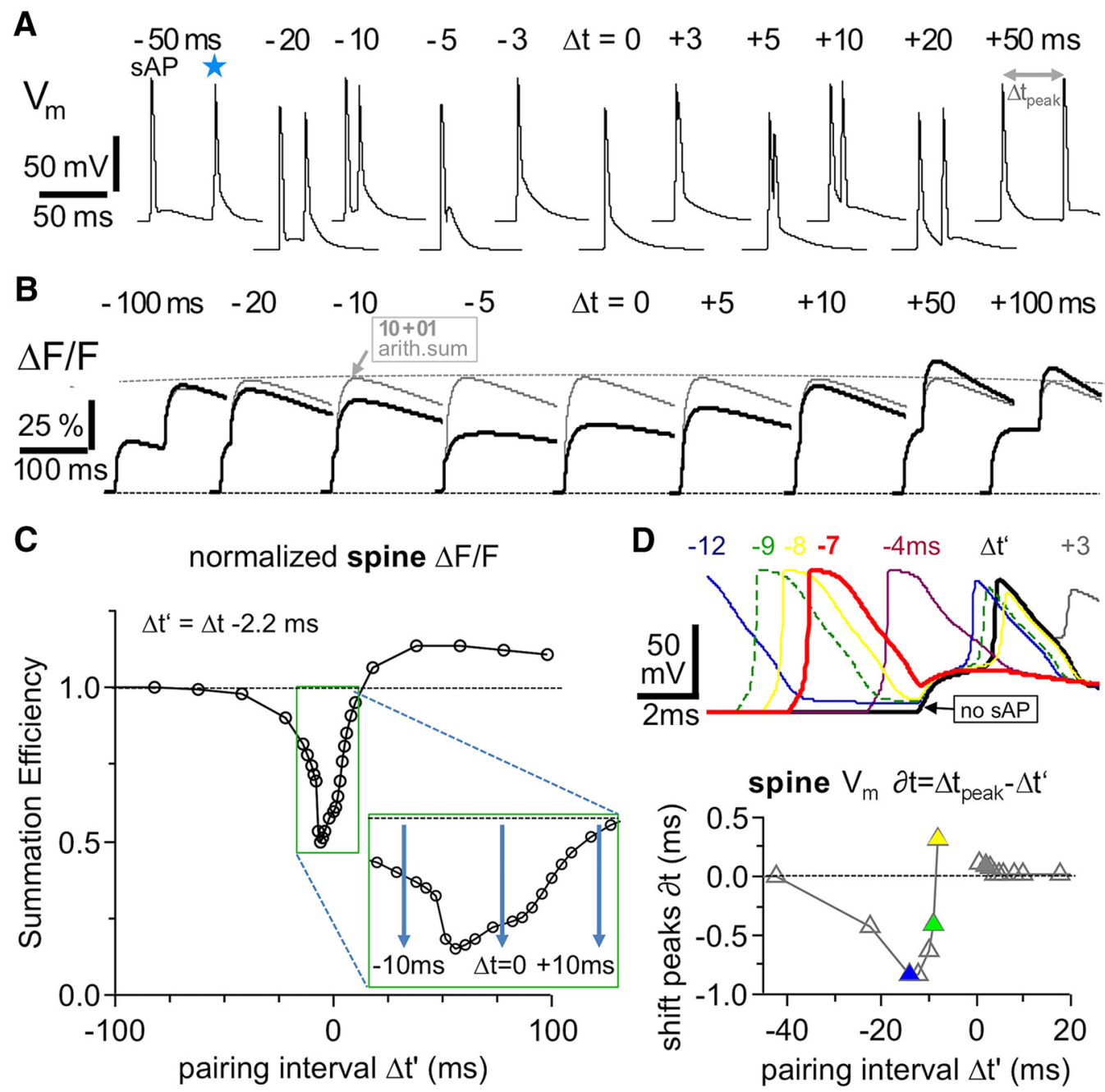

Figure 4. Simulated pairing of spine spike and global AP at various time intervals $\Delta$ t predicts SE. $A$, Simulation of $V_{m}$ at the spine head for spine spike and somatically evoked AP at various pairing intervals $\Delta \mathrm{t}$. Negative $\Delta \mathrm{t}$ corresponds to the sAP preceding the spine spike; positive $\Delta \mathrm{t}$ corresponds to the spine spike preceding the sAP. $\Delta \mathrm{t}$ is the difference between the respective stimulus onsets, whereas $\Delta \mathrm{t}^{\prime}$ denotes $\Delta \mathrm{t}$ corrected for the offset between the two peaks (top right). $\boldsymbol{B}$, Simulations of $\Delta \mathrm{F} / \mathrm{F}$ for various timing intervals $\Delta \mathrm{t}$ and comparison with the arithmetic sum of the individual responses from Figure 2 spaced by the same $\Delta \mathrm{t}$. C, SE, the maximal $\Delta \mathrm{F} / \mathrm{F}$ amplitude for each pairing divided by the maximal $\Delta \mathrm{F} / \mathrm{F}$ for the corresponding arithmetic sum, versus pairing interval $\Delta \mathrm{t}^{\prime}$ $\left(\Delta \mathrm{t}^{\prime}=\Delta \mathrm{t}-2.2 \mathrm{~ms}\right.$, corrected for the offset between the individual spikes). Inset, Magnification of the $\Delta$ t interval between $-10 \mathrm{~ms}$ and $10 \mathrm{~ms}$. $D$, Effect of pairing on actual time interval between the two spike peaks $\Delta \mathrm{t}_{\text {peaks }}$. Top, Simulated $V_{\mathrm{m}}$ at the spine head. Black line indicates spine spike simulation alone. Colored lines indicate pairing at the denoted $\Delta \mathrm{t}^{\prime}$ intervals (ms). Bottom, Deviation $\partial \mathrm{t}$ from the set interval $\Delta \mathrm{t}^{\prime}$, depending on $\Delta \mathrm{t}^{\prime}$. For increasingly negative intervals, there is first repulsion and then attraction.

individual signals underlying the arithmetic sum of a mean $(\Delta \mathrm{F} /$ $\mathrm{F})_{\text {syn }}=(\Delta \mathrm{F} / \mathrm{F})_{10}=36 \pm 17 \%$ and a mean $(\Delta \mathrm{F} / \mathrm{F})_{\mathrm{glAP}}=(\Delta \mathrm{F} / \mathrm{F})_{01}=$ $29 \pm 10 \%$, whereas the mean response to coincident signals was $(\Delta \mathrm{F} / \mathrm{F})_{\text {syn\&glAP }}=(\Delta \mathrm{F} / \mathrm{F})_{11}=73 \pm 17 \%$. Coincidence resulted, on average, in slightly supralinear summation. Summation of $\mathrm{Ca}^{2+}$ signals is evaluated in terms of SE, which here is defined as the maximal amplitude detected for the paired stimulation divided by the arithmetic sum of the two individual responses at the same interval $\Delta \mathrm{t}$. Thus, $\mathrm{SE}<1$ corresponds to sublinear summation, and $\mathrm{SE}>1$ corresponds to supralinear summation. For the described experiments, we obtained a mean $\mathrm{SE}=(\mathbf{1 1} /(\mathbf{1 0}+\mathbf{0 1}))=$ $1.15 \pm 0.21$ (median 1.21, with $p=0.017$ vs SE $=1.00$, Wilcoxon test). While supralinearity in itself is rather weak compared with, for example, the supralinearity observed for Hebbian EPSP-AP pairings at spines in other neuron types (e.g., SE $>1.5$ in Nevian and Sakmann, 2004), the main conclusion here is that SE is not sublinear, contrary to what would be predicted based on the spine spike phenomenon (see also Introduction). If no correction for contributions of the LTS to $(\Delta \mathrm{F} / \mathrm{F})_{\text {syn }}$ is made, the result is mostly linear and also clearly not sublinear $($ mean $\mathrm{SE}=1.08 \pm 0.22, p=$ 0.14 vs $\mathrm{SE}=1.00$ ).

Thus, we hypothesized that, in the above experiment, the spine spike and the global AP must occur with a substantial temporal offset to allow for the deinactivation of the involved voltage-gated conductances. We next turned to simulations to explore the relation between SE and the pairing interval $\Delta \mathrm{t}$ between the spikes (for a detailed description of the modeling approach, see Materials and Methods).

Simulation of $V_{\mathrm{m}}$ and $\Delta \mathrm{F} / \mathrm{F}$ for paired local and global spikes with variable pairing interval $\Delta \mathrm{t}$

Figure 4 shows simulations for various pairing intervals $\Delta t$. Here $\Delta \mathrm{t}$ denotes the interval between the respective stimulation onsets, in accordance with previous literature (e.g., Nevian and Sakmann, 2004). However, for the purpose of describing coincidence detection within a GC spine, a measurement of $\Delta t$ as the interval between the peaks of the sAP and the spine spike would be more exact because it is this interval that determines the 
mutual cancelling of voltage-dependent mechanisms, and the simulations predict a high sensitivity to it in the regimen between -5 and $-3 \mathrm{~ms}$ (Fig. $4 \mathrm{C}$ ). The conduction delay between the sAP peaks at the soma and at the spine is negligible $(<0.1 \mathrm{~ms}$, assuming a dendritic conduction velocity $\leq 1 \mathrm{~m} / \mathrm{s}$ ) (e.g., Stuart et al., 1997) and a mean distance between spine and soma $<100 \mu \mathrm{m}$ (own data above). The basal temporal offset between the peaks of the individual sAP and spine spike simulations from stimulation onwards was $-2.2 \mathrm{~ms}$ in our model, with the sAP in advance. In the following, the pairing interval corrected for this offset is denoted as $\Delta \mathrm{t}^{\prime}$, and $\Delta \mathrm{t}^{\prime}$ is also used for the $x$ axis in Figure $4 C$, which shows the SE curve.

As expected, the summation of sAPand spine spike-mediated $\mathrm{Ca}^{2+}$ signals was substantially sublinear with an SE $<0.75$ within a regimen from $-7 \mathrm{~ms}$ to +6 ms (i.e., a range of $\approx 15 \mathrm{~ms}$ ). The smallest SE value was found as 0.50 for $\Delta \mathrm{t}^{\prime}$ $\approx-6 \mathrm{~ms}$. For larger absolute pairing intervals, the SE rose to at least 1.0. Between $\Delta \mathrm{t}^{\prime}=-8 \mathrm{~ms}$ and $\Delta \mathrm{t}^{\prime}=-7 \mathrm{~ms}$, the simulated SE dropped in an almost step-like fashion. This sudden step also persisted for more closely spaced simulations using $0.1 \mathrm{~ms}$ steps (data not shown). In the positive or Hebbian direction, SE rose more steeply than in the negative direction and reached its maximal value of 1.22 at $\Delta \mathrm{t}^{\prime}=+40-60 \mathrm{~ms}$.

The actual interval between the two spikes was subject to bidirectional modulation for $\Delta \mathrm{t}^{\prime}$ values within the range of $-40 \mathrm{~ms}$ to $3 \mathrm{~ms}$; Figure $4 D$ shows $V_{\mathrm{m}}$ for a set of small $\Delta \mathrm{t}^{\prime}$ values and the relative shift of the spike interval $\partial \mathrm{t}$ versus $\Delta \mathrm{t}^{\prime}$. Naturally, this shift could not be determined for cancelled spine spikes or fully overlapping spikes, which happened between $\Delta \mathrm{t}^{\prime}=-7 \mathrm{~ms}$ and $\Delta \mathrm{t}^{\prime}=0 \mathrm{~ms}$. For larger negative $\Delta \mathrm{t}^{\prime}<-8 \mathrm{~ms}$ (Fig. $4 D$, yellow trace), there was an attractive effect that moved the spine spike more in advance by up to almost $1 \mathrm{~ms}$ at $\Delta \mathrm{t}^{\prime}=-12 \mathrm{~ms}$ (Fig. $4 D$, blue trace). This attraction is due to the sAP afterdepolarization that allows the spine head to reach AP threshold earlier upon synaptic input. At $\Delta \mathrm{t}^{\prime}=-8 \mathrm{~ms}$, there is a repulsive effect due to partial inactivation of $\mathrm{Na}_{\mathrm{v}}$ channels during the relative refractory period. At $\Delta \mathrm{t}^{\prime}=-7 \mathrm{~ms}$ (Fig. $4 D$, red trace), the spine spike is fully suppressed. The minimum of the SE curve is observed at $-6 \mathrm{~ms}$ because the next smaller intervals show a broadening of the sAP peak due to summation with the underlying EPSP that increases $\mathrm{Ca}_{\mathrm{v}}$-mediated $\mathrm{Ca}^{2+}$ entry (see $\Delta \mathrm{t}^{\prime}=-4 \mathrm{~ms}$ ). Once the sAP has passed the spine spike to the right toward positive pairing intervals, there is only a small suppression of the sAP waveform because the sAP-mediated depolarization of the entire neuron will spread passively into the spine head, even if the local $\mathrm{Na}_{\mathrm{v}}$ channels are inactivated in the wake of the spine spike (Fig. $4 D$, gray trace, $+3 \mathrm{~ms}$ ).

\section{Role of $\mathrm{Na}_{\mathrm{v}}$ channels and $\mathrm{Ca}^{2+}$ conductances (T-type and HVA-type $\mathrm{Ca}^{2+}$ channels, NMDARs) for SE and $\Delta \mathrm{F} / \mathrm{F}$ of paired signals}

We now ask to what extent the individual conductances in our model contribute to the $\mathrm{SE}$ for various $\Delta \mathrm{t}$ (Fig. 5, top panels). In the following, the conductances were selectively removed from the spine head compartment of the NEURON model (i.e., not from the parent dendrite) before running the simulation. Effects on $\Delta \mathrm{F} / \mathrm{F}$ without normalization are also shown (Fig. 5, bottom panels).

The selective removal of $\mathrm{Na}_{\mathrm{v}}$ channels from the spine head results in an SE curve that is very similar to $\mathrm{Ca}^{2+}$ SE curves in spines of other neuron types because, for negative $\Delta t$, there is (almost) no sublinear interaction; and for positive $\Delta t$, there is substantial supralinear summation (e.g., Nevian and Sakmann, 2004). In our case, the supralinear summation is stronger than for the full model because the NMDAR current is enhanced more efficiently by the sAP.

Removal of T-type $\mathrm{Ca}^{2+}$ channels results in a substantial reduction of the sublinearity; the rather sudden drop in SE between $\Delta \mathrm{t}=-40 \mathrm{~ms}$ and $-5 \mathrm{~ms}$ compared with control is due to the slower decay kinetics of T-type channels $\left(\tau_{1 / 2 \text { deact }} \approx 10 \mathrm{~ms}\right.$; see also Fig. 2B; and Materials and Methods). While in our basic model T-type channels mediate only $25 \%$ of the synaptic $\Delta \mathrm{F} / \mathrm{F}$ amplitude and $50 \%$ of the smaller $(\Delta \mathrm{F} / \mathrm{F})_{\mathrm{sAP}}$ amplitude, they play an important role in explaining sublinear summation.

Removal of HVA $\mathrm{Ca}^{2+}$ channels only slightly reduces sublinearity, with less impact on the overall shape of the SE curve compared with the case without T-type. The combined removal of T-type and HVA CC results in a reduced $\mathrm{Ca}^{2+}$ entry very similar to the situation without $\mathrm{Na}_{\mathrm{v}}$.

Finally, removal of NMDARs from the spine head results in an SE curve where the central sublinearity is maintained at almost the same relative strength and shape as for control, but there is no more asymmetry between the regimens of larger positive $\Delta t$ and larger negative $\Delta t$. Thus, as in other neurons, the supralinearity for positive $\Delta \mathrm{t}$ is due to NMDAR-mediated effects, although less pronounced because of the inherent activation of NMDARs during basal synaptic transmission. 


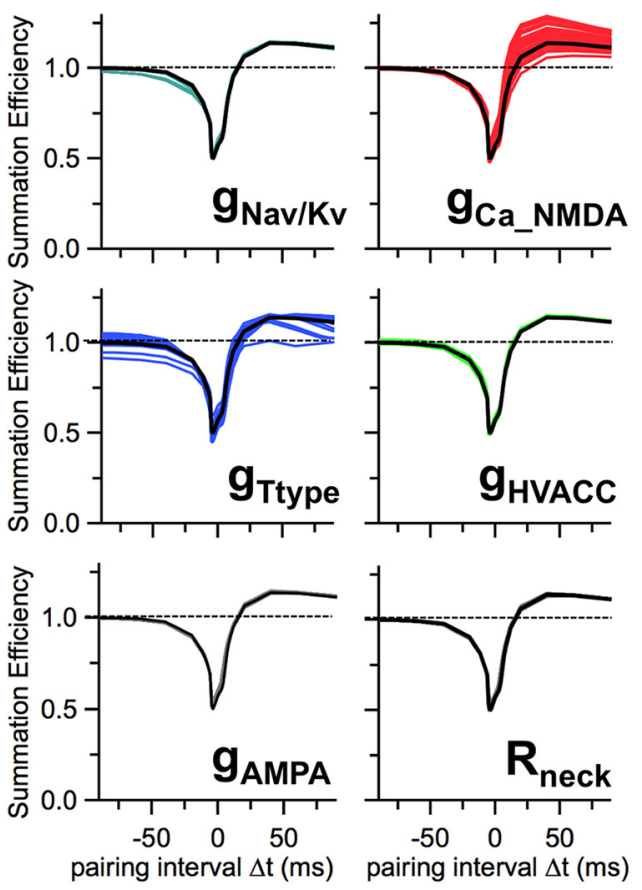

Figure 6. Robustness of simulation with respect to conductance densities in the spine head and $\mathrm{R}_{\text {Neck. }}$. Each plot represents the $\mathrm{SE}(\Delta \mathrm{t})$ from Figure $4 \mathrm{C}$ (black traces) and the random perturbations within a regimen of $50 \%-200 \%$ of the original values of the tested parameters (lighter colored or gray traces; $n=30$ for each parameter or less, if the perturbed model could not generate a full-blown spine spike). Each trace in each panel represents the model output for one different set of parameter values. The original values are given in Table 1, except for $R_{\text {Neck' }}$ which was $1.7 \mathrm{G} \Omega$ (because its value is derived from other NEURON parameters, see Materials and Methods). Tested parameters were the conductances for $\mathrm{Na}_{\mathrm{v}}$ and $\mathrm{K}_{\mathrm{v}}$ (covaried), the conductances for $\mathrm{Ca}^{2+}$ (for NMDAR, HVACC, and T-type C( each), the AMPAR conductance, and the neck resistance.

\section{Robustness of simulations}

We tested the robustness of the model with respect to the shape of $\operatorname{SE}(\Delta t)$ for all fast mechanisms and parameters that were not strongly constrained by previous experiments and that could impact SE, mainly the density of conductances within the spine head and the neck resistance. We did not test for changes in endogenous buffer capacity and well-established morphological and passive properties. Figure 6 shows $\mathrm{SE}(\Delta \mathrm{t})$ for variations of the total $\mathrm{Na}_{\mathrm{v}} / \mathrm{K}_{\mathrm{v}}$ conductances, of the individual $\mathrm{Ca}^{2+}$ conductances (NMDARs, T-type, HVACC) and the AMPAR conductance within the spine head, and of $R_{\text {Neck}}$. Parameter values were changed at random by up to a factor of 2 (i.e., between $50 \%$ and $200 \%$ of the model value). The model responded fairly robustly against these perturbations; most SE curves did not show substantial variations and, in particular, retained the central sublinearity.

Perturbing $\mathrm{Na}_{\mathrm{v}} / \mathrm{K}_{\mathrm{v}}$ conductances within the spine head had almost no effect on SE, as well as perturbations of the AMPAR conductance or the spine neck resistance $R_{\text {Neck }}$, provided that a full-blown spine spike could still be evoked (see Materials and Methods). Perturbation of $\mathrm{Ca}^{2+}$ entry via HVACCs also did not show any effect, whereas perturbation of $\mathrm{Ca}^{2+}$ entry via $\mathrm{T}$-type CCs reduced the maximal sublinearity by at most $20 \%$ but could also deepen it by $10 \%$ relative to the original model SE. Perturbations of the $\mathrm{Ca}^{2+}$ entry via NMDARs mostly reduced the maximal sublinearity (again by at most 20\%) and had substantial effects on supralinear summation at $40 \mathrm{~ms}$, increasing it to up to 1.29 or $>100 \%$ relative to the original supralinearity for enhanced NMDAR-mediated $\mathrm{Ca}^{2+}$ entry.

\section{Experimental test of simulation predictions}

To validate the basic features of the simulated SE curve, we next applied TPU to mimic local synaptic inputs and paired these with APs elicited by somatic current injection (sAPs) at pairing intervals of $-10,0$, and $10 \mathrm{~ms}$ in 9 GC spines. This spine population was located at a mean distance of $75 \pm 21 \mu \mathrm{m}$ from the soma and had a mean neck length of $2.6 \pm 1.1 \mu \mathrm{m}$.

Here pairing intervals $\Delta t$ refer to the stimulation onsets, not to the actual difference between the spine spike and somatic spike $V_{\mathrm{m}}$ peaks $\Delta \mathrm{t}_{\text {peaks }}$, because the spine spike $V_{\mathrm{m}}$ could not be detected directly. To establish the arithmetic sum of the two signals, we also recorded the responses to SAP and TPU stimulation alone; the mean individual signal amplitudes at the spine head $(\Delta \mathrm{F} / \mathrm{F})_{\mathrm{TPU}}=(\Delta \mathrm{F} / \mathrm{F})_{10}=37 \pm 21 \%$ and $(\Delta \mathrm{F} / \mathrm{F})_{\mathrm{sAP}}=(\Delta \mathrm{F} / \mathrm{F})_{01}=$ $28 \pm 12 \%$ closely overlapped with distributions of $(\Delta \mathrm{F} / \mathrm{F})_{\text {syn }}=$ $(\Delta \mathrm{F} / \mathrm{F})_{10}$ and $(\Delta \mathrm{F} / \mathrm{F})_{\mathrm{glAP}}=(\Delta \mathrm{F} / \mathrm{F})_{01}$ in the earlier reanalyzed coincidence dataset (Fig. 1; no significant differences, $p=0.32$ and $p=0.46$, respectively) and also matched the values of our basic model shown in Figure 3 with $(\Delta \mathrm{F} / \mathrm{F})_{\text {syn }}=40 \%,(\Delta \mathrm{F} / \mathrm{F})_{\text {sAP }}=$ $30 \%$. The same held for the sAP-mediated signal amplitude in the adjacent dendritic shafts, with $(\Delta \mathrm{F} / \mathrm{F})_{\mathrm{sAP}}=25 \pm 14 \%(p=0.26)$, but not for $(\Delta \mathrm{F} / \mathrm{F})_{\mathrm{TPU}}=3 \pm 7 \%$, which was smaller than the dendritic $(\Delta \mathrm{F} / \mathrm{F})_{\text {syn }}=12 \pm 7 \%(p=0.0025)$ because of contributions of global low-threshold spikes to the signals evoked by glomerular stimulation.

Figure 7 shows that pairing at $0 \mathrm{~ms}$ resulted in a highly significantly decreased signal compared with the arithmetic sum with $\mathrm{SE}=0.75 \pm 0.16(p<0.005)$, and pairing at $-10 \mathrm{~ms}$ was still sublinear in most cases $(\mathrm{SE}=0.85 \pm 0.28$, not significant), whereas pairing at $+10 \mathrm{~ms}$ resulted in supralinear summation to $1.12 \pm 0.30$ (not significant vs $\mathrm{SE}=1, p<0.05$ vs $\Delta t=-10 \mathrm{~ms}$ ).

There was no correlation between neck length and linearity of summation in the spine. In the adjacent dendrite, coincident inputs did not increase the spread of synaptic $\mathrm{Ca}^{2+}$ signal from the spine; thus, no pairing effects were observed (all three $\Delta t$, not significant vs $\mathrm{SE}=1$ ).

These results might be subject to statistical fluctuations, since due to the five different stimulation protocols (sAP alone, TPU alone, 11 for $0, \pm 10 \mathrm{~ms}$ ), we could not repeat measurements for each condition often enough to properly determine the mean and variance of the responses for each protocol (see Materials and Methods). Nevertheless, the results closely match the simulation (Fig. 7C).

The sublinearity of SE at $0 \mathrm{~ms}$ was slightly less substantial than the simulations imply. This deviation can be in part explained by the fact that in the experiment a precise control of the offset between the spine spike and the sAP is not possible because we lack information about the exact timing of the peak of the spine spike. Thus, the protocol $\Delta \mathrm{t}=0 \mathrm{~ms}$ might deviate from perfect coincidence by several milliseconds, which due to the steepness of the SE curve is likely to result in a reduced sublinearity, on average. As evident from Figure $7 C$, the SEs at $0 \mathrm{~ms}$ in individual experiments ranged from 0.54 to 0.98 , with $n=4$ experiments $<0.70$. The average experimental increase in SE between 0 and $+10 \mathrm{~ms}$ was 0.37 , and the simulated increase was 0.32 . Toward $-10 \mathrm{~ms}$, the experimental increase was just 0.10 , and the simulated increase was 0.19 .

\section{Analysis of time to peak for synaptically evoked APs}

Both simulations and experiments with artificially evoked APs and spine spikes show that a pairing at $\Delta \mathrm{t} \approx 0$ ms yields sublinear summation, whereas pairing at $\Delta \mathrm{t} \approx+10 \mathrm{~ms}$ results in linear or supralinear summation. To check whether a similar delay might 
A
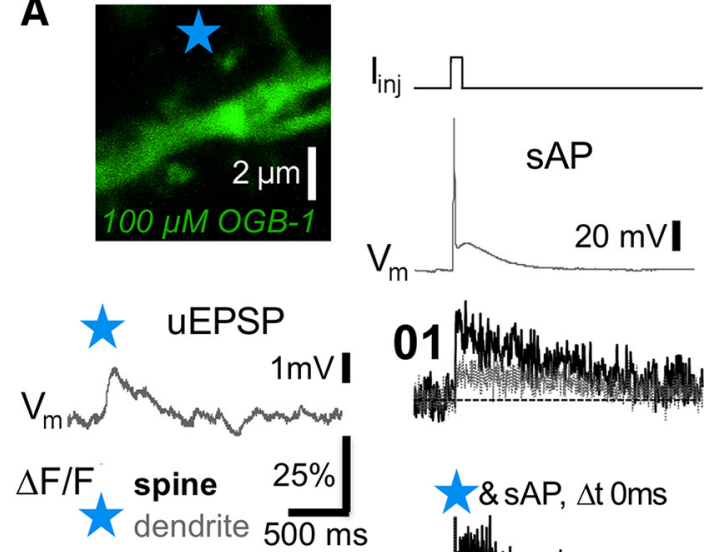

10
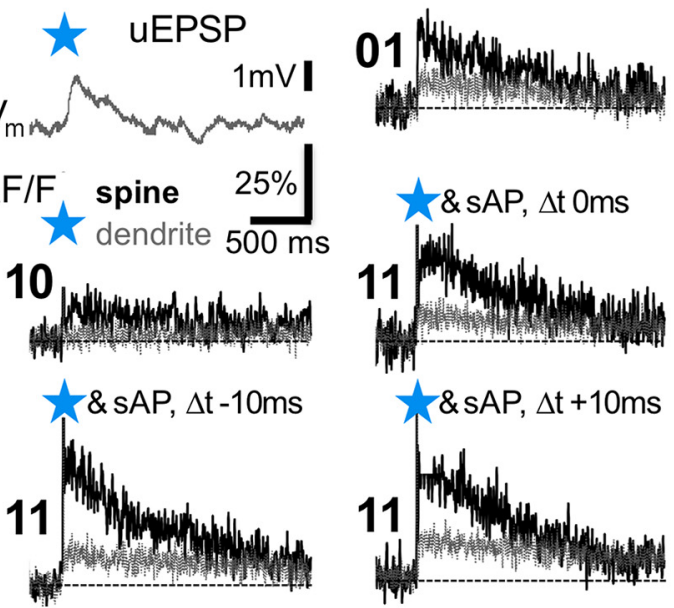

B

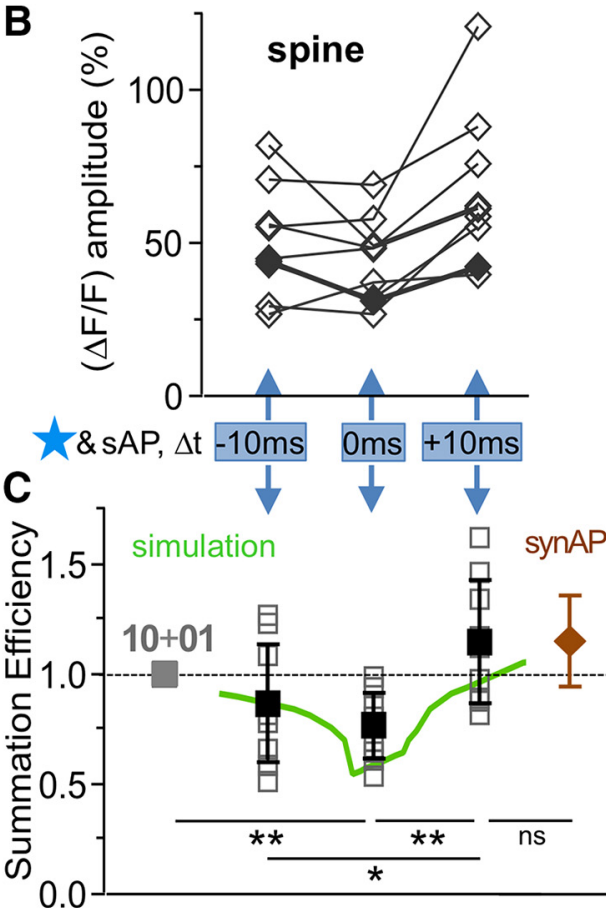

Figure 7. Experimental validation. TPU of glutamate at individual spines in coincidence with global APs for various $\Delta$ t values. $A$, Example of individual experiment. Scan of spine and dendrite with location of uncaging spot. Top, $V_{\mathrm{m}}$ recordings from $\mathrm{GC}$ soma of uncaging-evoked EPSP (uEPSP, left) or AP evoked by somatic current injection (sAP, right). Middle and bottom, Averaged fluorescence transients (line scans) across spine and adjacent dendrite. Five types of protocols: 10, uncaging at spine alone; $\mathbf{0 1}$, sAP alone, 3 times; $\mathbf{1 1}$, pairing of uncaging and sAP for three different intervals $-10,0$, and $+10 \mathrm{~ms}$. $B$, Cumulative graph of absolute $\Delta \mathrm{F} / \mathrm{F}$ amplitudes in response to the three pairing protocols for 9 individual experiments. Lines connect data points from one experiment. Solid diamonds represent the experiment shown in $\boldsymbol{A}$. C, Cumulative graph and statistical analysis of the associated summation efficiencies in response to the three pairing protocols. Open squares represent individual experiments. Solid squares represent mean. Error bars indicate SD. Rightmost data point indicates cumulative SE for coincident local input and synaptically evoked AP from Figure 1 ( for comparison. $p$ values of significance levels are given in Results. ${ }^{*} p<0.05 ; * * 0.01$.

also hold for synaptically evoked APs, we turned to our preexisting datasets of $V_{\mathrm{m}}$ recordings of APs evoked by glomerular stimulation of mitral cells (Egger, 2008) to analyze the latency between the EPSP onset and the AP peak (Fig. 8A). In these experiments, APs were evoked via glomerular stimulation of synaptic inputs and the stimulation strength was usually just above AP threshold. The mean latency was $9.8 \pm 8.4 \mathrm{~ms}(n=20$ cells $)$. In the subset of experiments where coincidence was observed (Fig. $1 C)$, the latency was $10.1 \pm 9.5 \mathrm{~ms}(n=7$ spines with detectable EPSP onset).

Again, the conduction time between soma and spine can be neglected (see above). Thus, the mean experimentally observed $\Delta \mathrm{t}$ is on the order of $10 \mathrm{~ms}$ or slightly below (if accounting for the time to peak of the spine spike), matching well with the observed $\mathrm{SE}$ at $\Delta \mathrm{t}=+10 \mathrm{~ms}$ (Fig. 7C, rightmost data point, taken from Fig. $1 C$, right; no significant difference to SE for $+10 \mathrm{~ms}$ in Fig. $7 C$, $p=0.37)$.

Simulation without added exogenous buffer and SE expected at physiological temperatures

In the experiments and simulations, the $\mathrm{Ca}^{2+}$ dye OGB-1 provides a substantial added buffer capacity (at $100 \mu \mathrm{M}: \kappa_{\mathrm{B}}=270$ ) that is considerably larger than the endogenous buffer capacitance $\left(\kappa_{\mathrm{E}}=100\right.$, Egger and Stroh, 2009). Thus, the dye will disrupt the endogenous $\mathrm{Ca}^{2+}$ dynamics and thereby also affect summation. To test whether the observed $\operatorname{SE}(\Delta t)$ is also likely to persist in the absence of exogenous buffer and thus to better estimate the summation of $\mathrm{Ca}^{2+}$ entry in physiological situations (e.g., during plasticity induction), we ran the simulations without added dye. As evident from Figure $8 B, C$, this situation results in a fairly similarly spaced SE regimen for negative $\Delta \mathrm{t}$ compared with the simulation with dye, whereas the supralinearity in SE for positive $\Delta \mathrm{t}$ is stronger, almost reaching 1.5 for $\Delta \mathrm{t}=+40 \mathrm{~ms}$ compared with the buffered case, and also the sublinearity is more pronounced. Thus, we predict the dynamic range of free $\mathrm{Ca}^{2+}$ levels following paired local and global activity to be substantially larger than in the situation with added dye, due to the saturation of the endogenous buffer, which might further enable differential signaling downstream of $\mathrm{Ca}^{2+}$ entry.

With respect to physiological temperature, there is only limited access to experimental data compared with the extended dataset at room temperature that constrains our model; therefore, we did not attempt to fully simulate the physiological situation at this point. Nevertheless, we have shown previously that at $34^{\circ} \mathrm{C}$ local $\mathrm{Na}_{\mathrm{v}}$ activation also happens in the GC spine following uncaging (Bywalez et al., 2015). The associated $(\Delta \mathrm{FF})_{\mathrm{TPU}}$ amplitude is similar to $(\Delta \mathrm{FF})_{\text {syn }}$ for room temperature $(38 \pm 23 \%, n=$ 5; analyzed from dataset in Bywalez et al., 2015). During sAPs, the total absolute $\mathrm{Ca}^{2+}$ entry is slightly decreased (by 20\%) and the decay of $\mathrm{Ca}^{2+}$ signals is roughly 2 times faster relative to room temperature values (Egger and Stroh, 2009). Because the latter effect will only weakly influence the summation of signals for $\Delta \mathrm{t}< \pm 50 \mathrm{~ms}$ and $\mathrm{Ca}^{2+}$ influx appears only slightly modified, we predict that the main results of our study should also be valid at physiological temperatures.

\section{Discussion}

The reciprocal spines of OB GCs have been shown to feature several types of $\mathrm{Ca}^{2+}$ signals, including local $\mathrm{Ca}^{2+}$ entry due to a local postsynaptically evoked AP and global $\mathrm{Ca}^{2+}$ influx in the 
A
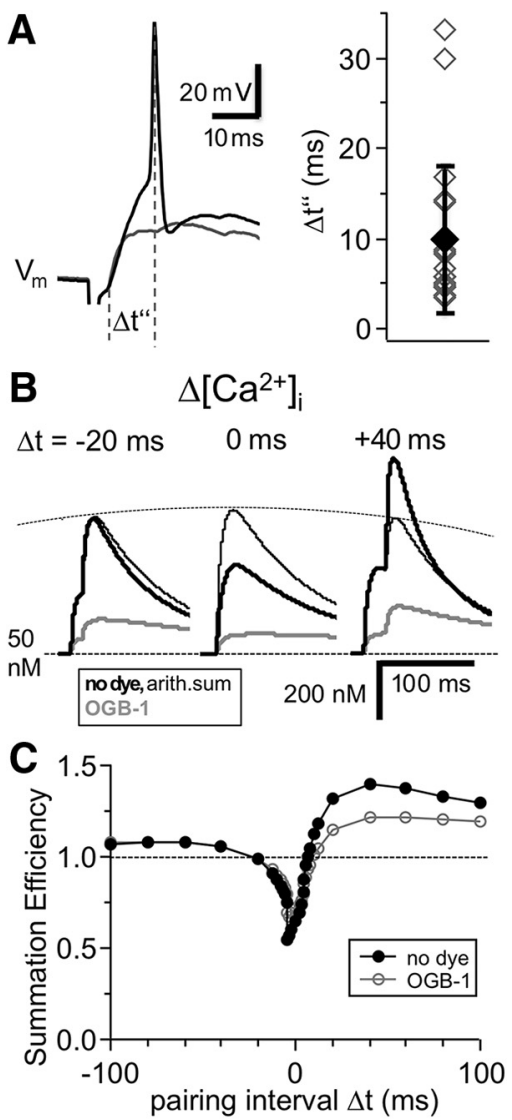

Figure 8. Latency of APs evoked by glomerular input and prediction of $\mathrm{Ca}^{2+}$ transients in the absence of dye. $A$, Analysis of the latency $\Delta t^{\prime \prime}$ between EPSP onset and AP peak for synaptically evoked GC APs. Left, Individual example somatic voltage recording of EPSP (gray trace) and AP (black trace). The stimulation artifact due to extracellular electrical stimulation of the glomerulus (compare Fig. $1 A, B$ ) is capped. Right, Cumulative data of latency $\Delta \mathrm{t}^{\prime \prime}$. Individual experiments (open diamonds) and mean value \pm SD (solid diamond). $\boldsymbol{B}$, Individual simulated $\left[\Delta \mathrm{Ca}^{2+}\right]_{i}$ transients for selected pairing intervals as to illustrate the increased dynamic range in the absence of exogenous buffer/dye (thick black traces). Thin black traces represent the arithmetic sum of local input and global AP $\mathbf{1 0}+\mathbf{0 1}$ in the absence of dye. Thick gray traces represent the simulated $\left[\Delta \mathrm{Ca}^{2+}\right]_{i}$ transients for the respective pairing intervals in the presence of $100 \mu \mathrm{m}$ 0GB-1 (which also underlie the respective $\Delta \mathrm{F} / \mathrm{F}$ transients shown in Fig. $4 B$ ). $C$, Predicted SE of $\left[\Delta \mathrm{Ca}^{2+}\right]_{i}$ in the absence of exogenous buffer/dye; result for dye plotted for comparison.

wake of global $\mathrm{Na}^{+}$and $\mathrm{Ca}^{2+}$ spikes. Here we investigated the interaction of local and global $\mathrm{Ca}^{2+}$ signals due to local postsynaptic APs and global AP firing, using both simulations and experiments.

Sublinear summation of coincident signals would be expected because of the inactivation of $\mathrm{Na}_{\mathrm{v}}$ and $\mathrm{Ca}_{\mathrm{v}}$ channels that are involved in both types of signals. The following back-of-theenvelope prediction is based on actual numbers from our previous publications and the assumption that the conductances carrying the sAP-mediated signal are completely inactivated by a coincident synaptic input. Thus, $(\Delta \mathrm{F} / \mathrm{F})_{\mathrm{sAP}} \approx 30 \%$ and $(\Delta \mathrm{F} / \mathrm{F})_{\text {syn }} \approx$ $40 \%$ (mean values from Egger et al., 2003, 2005) would yield a SE of $(\Delta \mathrm{F} / \mathrm{F})_{\text {syn }} /\left((\Delta \mathrm{F} / \mathrm{F})_{\text {syn }}+(\Delta \mathrm{F} / \mathrm{F})_{\text {sAP }}\right)=40 / 70=0.57$. This degree of sublinearity matches well with both the simulations and experimental findings for coincident signals shown here.

However, earlier experimental results indicated a linear or even supralinear summation of local synaptic inputs and global APs or $\mathrm{Ca}^{2+}$ spikes (Egger et al., 2005; Egger, 2008) (Fig. 1). This apparent contradiction can now be explained by a time delay between local input and global AP on the order of $\Delta \mathrm{t} \approx+10 \mathrm{~ms}$, with the local input preceding the global AP. In the anti-Hebbian situation (where the local input follows the global AP), our results predict that summation will reach the linear regimen at $\Delta \mathrm{t} \approx-40 \mathrm{~ms}$.

\section{Mechanisms}

As implied by our simulations, the postsynaptic local activation of $\mathrm{Na}_{\mathrm{v}}$ channels within the spine head is the cause of the observed sublinearity. Thus, in the absence of direct recordings of $V_{\mathrm{m}}$ at the GC spine head so far, our results provide additional evidence for the existence of the "spine spike."

Another major conclusion from our study is that the mechanisms incorporated in our model are sufficient to explain the observed phenomena; neither the metabotropic glutamate receptors nor the TRPC channels known to be present within the GC spines (Dong et al., 2009; Stroh et al., 2012) needed to be implemented. While metabotropic glutamate receptors play a role in coincidence detection at other synapses (e.g., in Purkinje cell, L2/3 pyramidal cell, and fast spiking cortical interneuron dendrites) (Wang et al., 2000; Nevian and Sakmann, 2006; Camiré and Topolnik, 2014), their contribution to coincidence detection at this synapse might be weak or negligible because their activation is not voltage-dependent. For TRPC14 channels, the situation is more complex because the triggering of synaptically evoked, TRPC-mediated plateau potentials did require coincidence with global APs (Egger, 2008; Stroh et al., 2012); this finding might be related to a dendritic localization of the activated TRPC channels and requires further studies.

While in our study the role of NMDARs is less pronounced than in the classical observations of coincidence detection at excitatory synapses (see Introduction), NMDARs still carry supralinear summation at positive pairing intervals. Our simulations underestimated the experimentally observed supralinearity at $+10 \mathrm{~ms}$, which on top varied broadly (Fig. 7C). Because perturbation analysis showed a strong dependence of supralinearity on the amount of NMDAR-mediated $\mathrm{Ca}^{2+}$ conductance (Fig. 6), there probably is a substantial variance in NMDAR contribution across synapses, as also indicated by our previous $\mathrm{Ca}^{2+}$ imaging data (Egger et al., 2005; Bywalez et al., 2015). Thus, future refinements of our model should include systematic variations of the NMDAR contribution and also strive for an improved representation of their $\mathrm{Ca}^{2+}$ conductance (e.g., by accounting for effects of increased $\left[\mathrm{Na}^{+}\right]_{\mathrm{i}}$ and $\left[\mathrm{Ca}^{2+}\right]_{i}$ on NMDAR conductance) (e.g., Yu and Salter, 1998; Hu et al., 2018).

Finally, T-type $\mathrm{Ca}^{2+}$ channels have been shown previously to play a major role in $\mathrm{GCCa}^{2+}$ signaling (Egger et al., 2003; Pinato and Midtgaard, 2003). In particular, GCs are capable of firing $\mathrm{Ca}^{2+}$ spikes upon synaptic stimulation, and these $\mathrm{Ca}^{2+}$ spikes also summate linearly with local synaptic inputs (Egger et al., 2005; Pinato and Midtgaard, 2005). While their $\operatorname{SE}(\Delta t)$ remains to be elucidated, we predict that the sublinearity for $\Delta \mathrm{t}=0 \mathrm{~ms}$ should be less substantial because of the smaller contribution of T-type CCs to the synaptic $\mathrm{Ca}^{2+}$ signal compared with the impact of $\mathrm{Na}_{\mathrm{v}}$ channels.

\section{Potential roles of summation for synaptic plasticity, release from the reciprocal spine, and network processing}

Long-term plasticity induction via short theta bursts at the mitral and tufted cell to GC synapse of the OB is NMDAR-dependent and does not require global GC spiking (Chatterjee et al., 2016), thus pairing of local and global signals is not involved in it. This observation might be related to the fact that NMDARs are already activated during unitary synaptic transmission via the boosting of AMPAR- 
mediated depolarization. Moreover, neither is $\Delta \mathrm{Ca}^{2+}$ as imaged at the spine head necessarily predictive of the direction of plasticity (Nevian and Sakmann, 2006), nor is a classical SE curve with supralinear summation for positive $\Delta \mathrm{t}$ and slightly sublinear summation for negative $\Delta \mathrm{t}$ a predictor for Hebbian-type spiketiming-dependent plasticity (e.g., compare Nevian and Sakmann, 2004 with Egger et al., 1999; see also Lisman and Spruston, 2010). In any case, it remains to be elucidated whether pairing of global APs with local inputs at $\Delta \mathrm{t} \geq \pm 10 \mathrm{~ms}$ can induce longterm plasticity at this synapse.

Because the reciprocal GC spine is both a postsynaptic and presynaptic structure, summation of postsynaptic $\mathrm{Ca}^{2+}$ signals in the reciprocal spine head most certainly has an impact on release of GABA from the spine. (Lage-Rupprecht et al., 2018) indicate that local activation of the GC spine results in a rather low release probability of on average $<0.3$. Thus, summation of $\mathrm{Ca}^{2+}$ signals might substantially enhance GABA release probability following either local synaptic input or also bAP invasion alone in a manner that is strongly dependent on $\Delta t$, with little enhancement for perfectly coincident signals and substantial enhancement for $\Delta \mathrm{t}$ within a range of $+10-50 \mathrm{~ms}$. GCs appear to fire rather sparsely but reliably in vivo during odor stimulation (e.g., Cang and Isaacson, 2003; Kato et al., 2012), and coactivation of mitral/tufted cells from within one glomerular column can already elicit global GC APs, as has been demonstrated via glomerular stimulation (Schoppa and Westbrook, 1999; Egger, 2008). Thus, summation of GC APs and local inputs is likely to play a role in recurrent inhibition within a glomerular column.

With respect to oscillatory network activity, it is tempting to speculate that the shape of $\operatorname{SE}(\Delta t)$ could contribute to the generation of fast gamma oscillations of the $\mathrm{OB}$, which several studies have allocated to recurrent MC-GC interactions (e.g., Lagier et al., 2004; Schoppa, 2006a,b; Fukunaga et al., 2014) and thus influence $\mathrm{OB}$ network activity. Here, the regimen of substantial sublinear summation was found to extend for a time window of $\approx 15 \mathrm{~ms}$ around $\Delta \mathrm{t}=0 \mathrm{~ms}$. In the wake of a synaptic global AP, the summation of $\mathrm{Ca}^{2+}$ entry within a coactivated reciprocal spine might increase its release probability within the following time interval, matching with gamma frequency. A similar delay between EPSP onset and GC AP firing on the order of $10 \mathrm{~ms}$ has been also observed in response to theta-burst-like stimulation (median $6.4 \mathrm{~ms}$ in Schoppa, 2006a). Because global $\mathrm{Na}^{+}$APs in GCs can drive synchronized inhibition across glomerular modules (Arnson and Strowbridge, 2017), local enhancement of gamma might also spread and interact with activity in other glomerular columns.

\section{Similar effects in spines of other neuron types}

The results described here might also be generalized to other spines of other neuron types whenever active conductances $\left(\mathrm{Na}_{\mathrm{v}}\right.$ and $\mathrm{Ca}_{\mathrm{v}}$ channels) in spines are already engaged during unitary synaptic transmission. Next to the presence of a sufficient density of $\mathrm{Na}_{\mathrm{v}}$ and $\mathrm{Ca}_{\mathrm{v}}$ channels, another prerequisite for such local activation is a substantial electrical compartmentalization of the spine head, which is by now discussed for spines in general (e.g., Tønnesen and Nägerl, 2016). For example, in dopaminergic neurons of the substantia nigra, $\mathrm{Na}_{\mathrm{v}}$ channels also can boost synaptic spine $\Delta \mathrm{Ca}^{2+}$ signals (Hage et al., 2016). Although changes in basal $V_{\mathrm{m}}$ during the pace-making cycle also play a substantial role, the summation of $(\Delta \mathrm{F} / \mathrm{F})_{\text {syn }}$ and $(\Delta \mathrm{F} / \mathrm{F})_{\mathrm{AP}}$ during ongoing tonic firing of the neuron showed a behavior highly reminiscent of the summation observed here (Hage et al., 2016, their Fig. 9). While $\Delta \mathrm{t}=0 \mathrm{~ms}$ was not investigated in these spines, we would predict that sublinear summation should occur for perfectly coincident EPSP- and global AP-mediated $\mathrm{Na}_{\mathrm{v}}$ channel activation.

Similarly, unitary postsynaptic activation of T-type channels was shown at strong parallel fiber-Purkinje cell synapses and was argued to possibly depend on a high $\mathrm{R}_{\text {neck }}$ (Ly et al., 2016), which might then summate with global climbing fiber activation. $\mathrm{Ca}_{\mathrm{v}}$ channels were also shown to be postsynaptically activated at hippocampal pyramidal neuron spines (Grunditz et al., 2008; Bloodgood et al., 2009). Thus, sublinear SE is highly likely to also occur at other synapses with strong electrical compartmentalization.

\section{References}

Arnson HA, Strowbridge BW (2017) Spatial structure of synchronized inhibition in the olfactory bulb. J Neurosci 37:10468-10480. CrossRef Medline

Beaulieu-Laroche L, Harnett MT (2018) Dendritic spines prevent synaptic voltage clamp. Neuron 97:75-82.e3. CrossRef Medline

Blackmer T, Kuo SP, Bender KJ, Apostolides PF, Trussell LO (2009) Dendritic calcium channels and their activation by synaptic signals in auditory coincidence detector neurons. J Neurophysiol 102:1218-1226. CrossRef Medline

Bloodgood BL, Giessel AJ, Sabatini BL (2009) Biphasic synaptic Ca influx arising from compartmentalized electrical signals in dendritic spines. PLoS Biol 7:e1000190. CrossRef Medline

Bywalez WG, Patirniche D, Rupprecht V, Stemmler M, Herz AV, Pálfi D, Rózsa B, Egger V (2015) Local postsynaptic voltage-gated sodium channel activation in dendritic spines of olfactory bulb granule cells. Neuron 85:590-601. CrossRef Medline

Camiré O, Topolnik L (2014) Dendritic calcium nonlinearities switch the direction of synaptic plasticity in fast-spiking interneurons. J Neurosci 34:3864-3877. CrossRef Medline

Cang J, Isaacson JS (2003) In vivo whole-cell recording of odor-evoked synaptic transmission in the rat olfactory bulb. J Neurosci 23:4108-4116. CrossRef Medline

Carnevale NT, Hines ML (2006) The NEURON book. Cambridge: Cambridge UP.

Chatterjee M, Pérez de los Cobos Pallarés F, Loebel A, Lukas M, Egger V (2016) Sniff-like patterned input results in long-term plasticity at the rat olfactory bulb and tufted cell to granule cell synapse. Neural Plasticity 2016:9124986. CrossRef Medline

Dong HW, Heinbockel T, Hamilton KA, Hayar A, Callaway J, Ennis M (2009) Metabotropic glutamate receptors and dendrodendritic synapses in the main olfactory bulb: International Symposium on Olfaction and Taste. Ann N Y Acad Sci 1170:224-238. CrossRef Medline

Egger V (2008) Synaptic sodium spikes trigger long-lasting depolarizations and slow calcium entry in rat olfactory bulb granule cells. Eur J Neurosci 27:2066-2075. CrossRef Medline

Egger V, Feldmeyer D, Sakmann B (1999) Coincidence detection and changes of synaptic efficacy in spiny stellate neurons in rat barrel cortex. Nat Neurosci 2:1098-1105. CrossRef Medline

Egger V, Stroh O (2009) Calcium buffering in rodent olfactory bulb granule cells and mitral cells. J Physiol 587:4467-4479. CrossRef Medline

Egger V, Svoboda K, Mainen ZF (2003) Mechanisms of lateral inhibition in the olfactory bulb: efficiency and modulation of spike-evoked calcium influx into granule cells. J Neurosci 23:7551-7558. CrossRef Medline

Egger V, Svoboda K, Mainen ZF (2005) Dendrodendritic synaptic signals in olfactory bulb granule cells: local spine boost and global low-threshold spike. J Neurosci 25:3521-3530. CrossRef Medline

Fukunaga I, Herb JT, Kollo M, Boyden ES, Schaefer AT (2014) Independent control of gamma and theta activity by distinct interneuron networks in the olfactory bulb. Nat Neurosci 17:1208-1216. CrossRef Medline

Grunditz A, Holbro N, Tian L, Zuo Y, Oertner TG (2008) Spine neck plasticity controls postsynaptic calcium signals through electrical compartmentalization. J Neurosci 28:13457-13466. CrossRef Medline

Hage TA, Sun Y, Khaliq ZM (2016) Electrical and $\mathrm{Ca}(2+)$ signaling in dendritic spines of substantia nigra dopaminergic neurons. eLife 5:e13905. CrossRef Medline

Hemond P, Epstein D, Boley A, Migliore M, Ascoli GA, Jaffe DB (2008) Distinct classes of pyramidal cells exhibit mutually exclusive firing patterns in hippocampal area CA3b. Hippocampus 18:411-424. CrossRef Medline 
Hines ML, Davison AP, Muller E (2009) NEURON and Python. Front Neuroinform 3:1. CrossRef Medline

Hu E, Mergenthal A, Bingham CS, Song D, Bouteiller JM, Berger TW (2018) A glutamatergic spine model to enable multi-scale modeling of nonlinear calcium dynamics. Front Comput Neurosci 12:58. CrossRef Medline

Isaacson JS, Vitten H (2003) GABA(B) receptors inhibit dendrodendritic transmission in the rat olfactory bulb. J Neurosci 23:2032-2039. CrossRef Medline

Kato HK, Chu MW, Isaacson JS, Komiyama T (2012) Dynamic sensory representations in the olfactory bulb: modulation by wakefulness and experience. Neuron 76:962-975. CrossRef Medline

Koester HJ, Sakmann B (1998) Calcium dynamics in single spines during coincident pre- and postsynaptic activity depend on relative timing of back-propagating action potentials and subthreshold excitatory postsynaptic potentials. Proc Natl Acad Sci U S A 95:9596-9601. CrossRef Medline

Lage-Rupprecht V, Ona Jodar T, Yeghiazaryan G, Rozsa B, Egger V (2018) Local reciprocal release of GABA from dendritic spines of olfactory bulb granule cells requires local sodium channel activation and occurs on both fast and slow timescales. BioRxiv. Available at http://biorxiv.org/cgi/ content/short/440198v1

Lagier S, Carleton A, Lledo PM (2004) Interplay between local GABAergic interneurons and relay neurons generates gamma oscillations in the rat olfactory bulb. J Neurosci 24:4382-4392. CrossRef Medline

Lester RA, Jahr CE (1992) NMDA channel behavior depends on agonist affinity. J Neurosci 12:635-643. CrossRef Medline

Lisman J, Spruston N (2010) Questions about STDP as a general model of synaptic plasticity. Front Synaptic Neurosci 2:140. CrossRef Medline

Ly R, Bouvier G, Szapiro G, Prosser HM, Randall AD, Kano M, Sakimura K, Isope P, Barbour B, Feltz A (2016) Contribution of postsynaptic T-type calcium channels to parallel fibre-Purkinje cell synaptic responses. J Physiol 594:915-936. CrossRef Medline

Maravall M, Mainen ZF, Sabatini BL, Svoboda K (2000) Estimating intracellular calcium concentrations and buffering without wavelength ratioing. Biophys J 78:2655-2667. CrossRef Medline

Markram H, Roth A, Helmchen F (1998) Competitive calcium binding: implications for dendritic calcium signaling. J Comput Neurosci 5:331-348. CrossRef Medline

Migliore M, Cook EP, Jaffe DB, Turner DA, Johnston D (1995) Computer simulations of morphologically reconstructed CA3 hippocampal neurons. J Neurophysiol 73:1157-1168. CrossRef Medline

Nevian T, Sakmann B (2004) Single spine $\mathrm{Ca}^{2+}$ signals evoked by coincident EPSPs and backpropagating action potentials in spiny stellate cells of layer 4 in the juvenile rat somatosensory barrel cortex. J Neurosci 24: 1689-1699. CrossRef Medline

Nevian T, Sakmann B (2006) Spine $\mathrm{Ca}^{2+}$ signaling in spike-timingdependent plasticity. J Neurosci 26:11001-11013. CrossRef Medline

Nunes D, Kuner T (2018) Axonal sodium channel NaV1.2 drives granule cell dendritic GABA release and rapid odor discrimination. PLoS Biol 16:e2003816. CrossRef Medline

Ona-Jodar T, Gerkau NJ, Sara Aghvami S, Rose CR, Egger V (2017) Twophoton $\mathrm{Na}(+)$ imaging reports somatically evoked action potentials in rat olfactory bulb mitral and granule cell neurites. Front Cell Neurosci 11:50. CrossRef Medline
Pinato G, Midtgaard J (2003) Regulation of granule cell excitability by a low-threshold calcium spike in turtle olfactory bulb. J Neurophysiol 90: 3341-3351. CrossRef Medline

Pinato G, Midtgaard J (2005) Dendritic sodium spikelets and low-threshold calcium spikes in turtle olfactory bulb granule cells. J Neurophysiol 93: 1285-1294. CrossRef Medline

Schiller J, Schiller Y, Clapham DE (1998) NMDA receptors amplify calcium influx into dendritic spines during associative pre- and postsynaptic activation. Nat Neurosci 1:114-118. CrossRef Medline

Schoppa NE (2006a) Synchronization of olfactory bulb mitral cells by precisely timed inhibitory inputs. Neuron 49:271-283. CrossRef Medline

Schoppa NE (2006b) AMPA/kainate receptors drive rapid output and precise synchrony in olfactory bulb granule cells. J Neurosci 26:1299613006. CrossRef Medline

Schoppa NE, Westbrook GL (1999) Regulation of synaptic timing in the olfactory bulb by an A-type potassium current. Nat Neurosci 2:11061113. CrossRef Medline

Schoppa NE, Kinzie JM, Sahara Y, Segerson TP, Westbrook GL (1998) Dendrodendritic inhibition in the olfactory bulb is driven by NMDA receptors. J Neurosci 18:6790-6802. CrossRef Medline

Sobol IM (2001) Global sensitivity indices for nonlinear mathematical models and their Monte Carlo estimates. Math Comput Simul 55:271280. CrossRef

Stroh O, Freichel M, Kretz O, Birnbaumer L, Hartmann J, Egger V (2012) NMDA-receptor dependent synaptic activation of TRPC channels in olfactory bulb granule cells. J Neurosci 32:5737-5746. CrossRef Medline

Stuart GJ, Häusser M (2001) Dendritic coincidence detection of EPSPs and action potentials. Nat Neurosci 4:63-71. CrossRef Medline

Stuart G, Spruston N, Sakmann B, Häusser M (1997) Action potential initiation and backpropagation in neurons of the mammalian CNS. Trends Neurosci 20:125-131. CrossRef Medline

Tønnesen J, Nägerl UV (2016) Dendritic spines as tunable regulators of synaptic signals. Front Psychiatry 7:101. CrossRef Medline

Wang SS, Denk W, Häusser M (2000) Coincidence detection in single dendritic spines mediated by calcium release. Nat Neurosci 3:1266-1273. CrossRef Medline

Waters J, Schaefer A, Sakmann B (2005) Backpropagating action potentials in neurones: measurement, mechanisms and potential functions. Prog Biophys Mol Biol 87:145-170. CrossRef Medline

Woolf TB, Shepherd GM, Greer CA (1991) Serial reconstructions of granule cell spines in the mammalian olfactory bulb. Synapse 7:181-192. CrossRef Medline

Xiong W, Chen WR (2002) Dynamic gating of spike propagation in the mitral cell lateral dendrites. Neuron 34:115-126. CrossRef Medline

Yu XM, Salter MW (1998) Gain control of NMDA-receptor currents by intracellular sodium. Nature 396:469-474. CrossRef Medline

Yuste R, Denk W (1995) Dendritic spines as basic functional units of neuronal integration. Nature 375:682-684. CrossRef Medline

Yuste R, Majewska A, Cash SS, Denk W (1999) Mechanisms of calcium influx into hippocampal spines: heterogeneity among spines, coincidence detection by NMDA receptors, and optical quantal analysis. J Neurosci 19:1976-1987. CrossRef Medline 